\title{
Differential effect of high fat diet (HFD) on the cardiac muscle of adult and aged female mice and the possible protective role of artichoke treatment: Histomorphometric and ultrastructural study
}

\section{Original Article}

\author{
Asmaa F. A. Dawood ${ }^{1}$ and Hemmat H.G. Hareedy ${ }^{2}$ \\ ${ }^{1}$ Department of Histology, Faculty of Medicine, Assiut University, Assiut, Egypt, Department \\ of Biomedical Science, Faculty of Medicine, King Faisal University, Alhasa, Saudi Arabia, \\ ${ }^{2}$ Department of Basic Medicine, Majma'ah University, Saudi Arabia.
}

\begin{abstract}
Background: Coexistence of hyperlipidemia and aging is a highly serious condition that massively deteriorates cardiac function. Artichoke is a well-known antioxidant commonly used in long-lived countries diet. Recent researches showed its hypolipidemic and antiaging effects.

Objective: This work aimed to investigate the histopathological effects of high fat diet (HFD) on adult mice cardiac muscle, to address and compare the extent of myocardial damage in aged mice and to assess beneficial effects of artichoke in mitigating these effects.

Materials and Methods: A total of 42 adult (Group I) and aged (Group II) female mice (3 and 26 months old respectively) were divided into six equal subgroups (7 per each); Groups Ia and IIa: adult and aged control, Groups Ib and IIb: adult and aged HFD groups were fed diet enriched with $1.5 \%$ cholesterol and 10\% lard oil for 6 weeks. Groups Ic and IIc: adult and aged artichoke treated group, were received HFD for 6 weeks as HFD groups concomitant with artichoke extract at a dose of $1.5 \mathrm{gm} / \mathrm{kg}$ once daily via gastric tube.

Results: Adult HFD laden cardiac myocytes showed loss of cross striations, inflammatory cell infiltrate, increase collagen content, myofiber focal degeneration, disruption of myofibrils, sarcomeres and T tubule system, lipid vacuolation, mitochondrial damage and nuclear pyknosis. These effects were the worst in aged HFD fed animals. Artichoke markedly improved these changes in both adult and aged mice.

Conclusion: combination of HFD and aging caused more extensive insults on cardiac myocytes than each factor alone. Artichoke is highly efficient in ameliorating these insults.
\end{abstract}

Key Words: HFD, fibrillolysis, cristolysis, sarcopenia, artichoke.

Revised: 06 April 2019, Accepted: 25 June 2019

Corresponding Author: Asmaa F. A. Dawood, Ph.D, Department of Histology, Faculty of Medicine, Assiut University, Assiut, Egypt, Department of Biomedical Science, Faculty of Medicine, King Faisal University, Alhasa, Saudi Arabia, Tel.: +966568902355, E-mail: asmaanoorahmed@yahoo.com

ISSN:2536-9172, June 2019, Vol. 3, No. 1

\section{INTRODUCTION}

The prevalence of obesity has increased at an alarming rate during the last two decades. It has almost reached to epidemic proportions and this appears to be more pronounced in women. Changes in food consumption, physical activity, urbanization, socioeconomic and demographic factors are being important factors that contribute to the increased prevalence of obesity ${ }^{[1]}$.

Lipotoxic cardiac morbidity is one of the most serious consequences of obesity in human. In both human and animal models, lipotoxicity resulted in diverse myocardial dysfunction including left ventricular chamber dilation, cardiac hypertrophy, contractile dysfunction, atrial fibrillation and ventricular extrasystoles ${ }^{[2]}$. One of the most serious and fatal complications of morbid obesity is congestive heart failure which occurs even in absence of hypertension or underlying organic cardiac disease ${ }^{[3]}$.

Aging is a natural process which is associated with gradual decline in biological functions, that directly affects lifestyle. Aging remains the single major risk factor for heart attacks, stroke, diabetes, cancers, and most chronic diseases $^{[4]}$. With the current increase in life expectancy, the prevalence of obesity also raises steadily among elderly people. Both obesity and aging can lead to serious health problems mainly cardiac diseases that can lead to death. Aging is associated with an increase in abdominal obesity, a major contributor to insulin resistance and the metabolic syndrome $\mathrm{e}^{[5]}$. Obesity in the elderly is thus a serious concern and comprehension of the related histopathological changes and the key underlying mechanisms become a necessary matter ${ }^{[4]}$. Actually, studies of histological and ultrastructural alterations of cardiac muscle in case of HFD 
feeding in adult or when associated with aging are very limited. Moreover, little is known about the protective effect of concomitant treatment with antioxidants on aged HFD laden myocardium.

Antisteatotic drugs are commonly used in treatment plan of hyperlipidemia but recent researches have reported their adverse effects on human health. Thereby, nowadays there is increasing interest for the use of natural lipid-lowering agents that may delay or circumvent drug therapy ${ }^{[6]}$.

Artichoke (Cynarascolymus) is a plant frequently grown in Mediterranean countries. It is highly rich in natural active antioxidant ingredients and thus is commonly used as an herbal drug ${ }^{[7]}$. Recent investigations have suggested that artichoke extract has potential lipid-lowering, hepatoprotectiveand also antiaging effects on $\operatorname{skin}^{[8,9]}$. However, its potential role against cardiac lipotoxicityis not yet investigated.

Accordingly, the present study aimed to address the histopathological effects of HFD feeding on cardiac muscle of aged mice, comparing such impact with that on adult myocardium and to demonstrate the beneficial effects of artichoke in mitigating lipotoxic cardiac damage.

\section{MATERIALS AND METHODS}

\section{Chemicals:}

Cholesterol and Lard oil were purchased from Sigma Chemical (St. Louis, MO.USA). They were added to standard diet at a percentage of 1.5 and $10 \%$ respectively. The high fat diet was freshly prepared every week and stored at $4 \mathrm{C}$.

Artichoke was provided in the form of commercial capsules (MEPACO- EGYPT -Enshas El Raml- Sharkeiya) sold in the market as Cyncholine 100mg. A suspension was made by mixing the content of the capsules with distilled water(each $100 \mathrm{mg}$ was dissolved in $5 \mathrm{ml}$ distilled water).

\section{Animals:}

Forty-two adult and aged female albino mice (21 for each) were used in the current study. They were provided by animal house of AssiutUniversity, Assiut, Egypt. Adult and old mice were 3 month-old (25-30gm) and 26-month old (40-50gm). All animals were kept in clean ventilated stainless-steel cages under controlled laboratory conditions. They were allowed free access to water andwere under daily weight monitoring. All procedures on experimental animals were overseen and approved by ethical Committee, faculty of Medicine, Assiut University, Egypt.

\section{Experimental design:}

Adult mice (Group I) and aged mice (Group II) were equally subdivided into six subgroups (7 per subgroup) as the following:

1) Adult control (Ia) and aged control (IIa) groups: Control animals were fed standard chow diet for 6 weeks.

2) Adult HFD treated (Ib) and aged HFD treated (IIb) groups:

High fat diet treated adult and aged mice were fed HFD composed of standard chow diet supplemented with $1.5 \%$ cholestero ${ }^{[10]}$ and $10 \%$ Lard oil $^{[11]}$ for 6 weeks.

3) Adult artichoke treated (Ic) and aged artichoke treated (IIc)groups:

Groups Ic and IIc were fed HFD for 6 weeks as HFD treated animals. They concomitantly received artichoke extract at a dose of $1.5 \mathrm{gm} / \mathrm{kg} /$ day $^{[12]}$ via gastric tube for 6 weeks.

Under general anesthesia using chloroform, all animals were sacrificed. Hearts were taken, immediately fixed in $10 \%$ Formalin and processed for histological, ultrastructural and morphometric study.

\section{Light microscopy:}

Specimens from the base of the heart were dissected then processed for general histological examination of left ventricles using Hematoxylin \& Eosin (H\&E) and Masson trichrome stains ${ }^{[13]}$.

\section{Electron microscopy:}

For semithin and ultrathin sections, small specimens from left ventricles were fixed in 2-3\% Glutaraldehyde, kept in the fridge overnight then processed and post fixed in osmium tetra oxide. Semithin sections were cut, stained with Toluidine blue stain, examined, photographed then used to select specific areas for preparing ultrathin-sections of the electron microscope.

Ultrathin sections were cut and stained with uranyl acetate and lead citrate, examined and photographed with a JEOL (JEM-100cx) transmission electron microscope in Assiut University Electron Microscope unit ${ }^{[14]}$.

\section{Morphometric study:}

Myocyte number and diameter were estimated as follow:

\section{1) Cardiac myocyte number:}

In $\mathrm{H}$ \& $\mathrm{E}$ stained cross sections, myocyte number was estimated by counting nuclei number. Ten sections were used for each group. For each section, six images were scanned and nuclei number was estimated at 100x magnification by using point counting method with a computerized image analyzer system software (Leica Q 500 MCO; Leica, Germany ${ }^{[15]}$. 


\section{2) Cardiac myocyte diameter:}

In $\mathrm{H} \& \mathrm{E}$ stained sections, five random regions from each slide at $100 \mathrm{x}$ magnification and 10 myocytes were measured from each section. A total of 100 cell was measured per animal. Diameter was measured in $(\mu \mathrm{m})$ across the nuclei, for those only containing nuclei using a calibrated ocular micrometer scale. Branching sites were excluded from measurement. For calibration, stage micrometer was used ${ }^{[15,16]}$.

Statistical data Analysis (SPSS) of results was done using (ANOVA test) and Mann Whitney $U$ test for pair comparison of means among groups. Results were expressed as mean and standard deviation (mean $\pm \mathrm{SD}$ ). $\mathrm{P}$ value less than 0.05 was considered significant.

\section{RESULTS}

\section{Light microscope examination:}

\section{1) $H \& E$ and semithin stained longitudinal sections:}

$\mathrm{H} \& \mathrm{E}$ stained sections of left ventricle of adult control group (Ia) revealed individual cardiac myocytes were cylindricalin shape that branch and anastomose forming three-dimensional network. Their sarcoplasm was highly acidophilic, crossly striated and bearing a single central oval and vesicular nucleus. Narrow spaces of endomysium were seen among myocytes. Few fibroblasts having flat dense nuclei were observed at periphery of myocytes residing endomyium (Figs. 1 and 2). In semithin sections, cardiac myocytes were closely packed and branched forming a continuous syncytium separated by narrow endomysial spaces richly supplied in blood capillaries. Sarcoplasm showed obvious cross striations and had single oval vesicular nucleus. Intercalated discs appeared as deeply stained transverse lines among myocytes (Fig. 3).

$\mathrm{H} \& \mathrm{E}$ stained sections of left ventricle of adult HFD treated group (Ib) revealed that muscle fibers were obviously affected compared with group Ia. Foci of myofiber loss and lysis in addition to local inflammatory cell infiltration were noticed. Sarcoplasm lost its cross striations and nuclei appeared shrunken. Moreover, many fibroblast nuclei were apparently increased compared with group Ia (Figs. 4 and 5). In semithin sections, some areas of muscle fibers were lost and patches of sarcoplasm appeared pale. Nuclei were pyknotic. Intercellular spaces showed some inflammatory cell infiltrate and were markedly enlarged with encroachment of connective tissue to adjacent myocytes (Fig. 6).

In $\mathrm{H} \& \mathrm{E}$ stained and semithin sections of left ventricle of adult artichoke treated group (Ic), cardiac muscle fibers were obviously improved compared with group Ib. Cardiomyocytes were branched and abut together forming closely packed network with minor endomysium in between. There was no detected foci of degeneration or local inflammatory cell infiltrate. Sarcoplasm had cross striations similar to group Ia and most nuclei appeared oval and vesicular but few of them were still affected. Some fibroblast nuclei appeared in sections similar to group Ia (Figs. 7, 8 and 9). Intercalated discs among myocytes and rich capillary vessels were also observed similar to group Ia (Fig. 9).

H\&E stained and semithin sections of left ventricle of aged control group (IIa) showed remarkable changes compared with group Ia. Disturbed architecture was clearly noticed. Muscle fibers became loosely packed with widening of intercellular spaces. Sarcoplasm of most muscle fibers was pale acidophilic, degenerated and lacked its cross striations. Most nuclei were dense and shrunken (Figs. 10, 11 and 12). Many fibroblasts were also noticed unlike group Ia (Fig. 10).

In H\&E and semithin stained sections of left ventricle of aged HFD group (IIb), cardiac tissue damage and disruption is more pronounced than groups IIa and $\mathrm{Ib}$. Many muscle fibers were lost with subsequent marked widening of intercellular spaces. Some inflammatory cell infiltrate and congestion of blood vessels were noticed. Some myocytes showed focal degeneration while some others had wavy corrugated appearance. Sarcoplasm was pale, disintegrated and lost its cross striations and nuclei were dense and pyknotic (Figs. 13, 14 and 15). Fibroblast population were noticeably increased and apparently appeared as the most abundant fibroblast pool when compared with all other groups (Fig. 13).

$\mathrm{H} \& \mathrm{E}$ and semithin stained sections of left ventricle of aged artichoke treated group (IIc), cardiac muscle fibers were remarkably improved compared with other aged groups. No foci of muscle lysis or corrugation or inflammatory cell infiltration was noticed. Myocytes appeared branched with narrow intercellular spaces. Sarcoplasm was deeply acidophilic and crossly striated. Some nuclei seemed normal while others were shrunken. Fibroblast population apparently much decreased compared with other aged groups (Figs. 16, 17 and 18). In addition, intercalated discs were seen among myocytes (Fig. 18).

\section{2) Masson trichrome stained longitudinal sections:}

Masson trichrome stained sections of left ventricle of group Ia showed scanty collagen fibers were seen around blood vessels and among muscle fibers (Fig. 19).

In group Ib, Masson trichrome stained sections of left ventricle showed the amount of collagen fibers was remarkably increased among myocytes and around blood vessels compared with group Ia that encroaching adjacent muscle fibers (Fig. 20).

The amount of collagen fibers in Masson trichrome stained sections of group Ic was obviously decreased 
compared with group $\mathrm{Ib}$ and it seemed almost normal among muscle fibers (Fig. 21).

Masson trichrome stained sections of left ventricle of group IIa revealed increased amount of collagen fibers that encroaching myofibers compared to group Ia (Fig. 22).

In groupIIb, Masson trichrome stained sections of left ventricle showed increased amount of collagen fibers replacing many muscle fibers with obvious widening of intercellular spaces (Fig. 23).

Masson trichrome stained sections of left ventricle of group IIc showed decreased amount of collagen fibers among myocytes compared with other aged groups (Fig. 24).

\section{Electron microscope examination:}

In adult control group (Ia), most sarcoplasm of muscle fibers was occupied with longitudinal parallel arrays of cylindrical myofibrils. Their nuclei were oval central and euchromatic. Abundant number of large mitochondria were seen juxtanuclear and run among and parallel to myofibrils. Mitochondria were oval or rounded and possessed densely packed cristae. Each sarcomere was bounded by two $\mathrm{Z}$ lines and was composed of central dark (A) band and peripheral two halves of light (I) band. $\mathrm{H}$ band appeared as narrow light zone in the center of $\mathrm{A}$ band and was bisected by dark $\mathrm{M}$ line. Steplike intercalated discs were seen among myocytes. They were composed of transverse regions containing desmosomes and fascia adherens and longitudinal regions representing gap junctions. Glycogen granules appeared as small dense granules among myofibrils. Sarcolemma was intact, scalloped and showed invaginations of $\mathrm{T}$ tubules opposite $\mathrm{Z}$ lines. Terminal cisternae of sarcoplasmic reticulum and $\mathrm{T}$ tubules constituted diads which were noticed in sarcoplasm at the level of $Z$ line (Figs. 25 and 26).

In adult HFD treated group (Ib), intramyocellular accumulation of lipid vacuoles was observed so close to mitochondria. Mitochondria had partially damaged cristae. Moreover, thinning and splitting of myofibrils and focal myofibrillar lysis were noticed. Sarcomere showed obvious degeneration; A and I bands were not detectable and $\mathrm{Z}$ lines were disrupted and hazy. Nuclei appeared shrunken, heterochromatic, had irregular outlines and dilated perinuclear cisternae. Sarcolemma lost its scalloping appearance and appeared mostly smooth lacking its grooves of T tubules (Figs. 27 and 28).

Ultrathin sections of cardiac muscle of adult artichoke treated group (Ic) showed noticeable improvement in architecture compared with group Ib. Myofibrils seemed normal with no foci of degeneration or splitting except for few thin sparse myofibrils. Successive sarcomeres and $\mathrm{Z}$ lines appeared normal. Mitochondria had intact densely packed cristae, no lipid vacuoles were noticed and sarcolemma exhibited scalloped appearance similar to adult control group (Figs. 29 and 30).

Ultrathin sections of aged control group (Group IIa) revealed obvious changes compared with group Ia. Abundant large mitochondria were seen apparently occupy most sarcoplasm compared with scanty myofibrils. Many mitochondria appeared large with intact closely packed cristae while other had damaged and loosely packed cristae. Myofibrils were thin and showed obvious splitting of its myofilaments. Sarcomeres had narrow lighter A band and hazy $Z$ lines. Sarcolemma was scalloped at $Z$ line almost like normal. Nucleus was oval, deeply indented and had irregular outlines. It had prominent nucleolus and few heterochromatin clumps (Figs. 31 and 32).

In aged HFD treated group (IIb), ultrathin sections showed the most extensive damage and disruption of architecture of cardiac muscle compared with all other groups in the study. There was complete lysis of many myofibrils with widening of intermyofibrillar space. Other myofibrils were thin or showed splitting of its myofilaments. Noticeably, sarcomeres were disintegrated; $\mathrm{A}$, I and $\mathrm{H}$ bands could not be distinguished and $\mathrm{Z}$ lines were disrupted in most sections. Simultaneously, complete damage and degeneration of many mitochondria were noticed and others were partially damaged. Sarcolemma was disrupted and lost its grooves in most sections. Nuclei exhibited irregular and indented outlines (Figs. 33 and 34)

Ultrathin sections of aged artichoke treated group (IIc) were improved compared with groups IIa and IIb. Most sarcoplasm was filled with myofibrils unlike other aged groups. Many myofibrils were cylindrical and formed longitudinal parallel arrays with narrow interfibrillar spaces but few of them were still thin and split. Their sarcomeres were improved; A, I and $\mathrm{H}$ bands were clearly seen and Z lines were intact. Mitochondria were partially improved; some of them exhibited intact cristae and others were still damaged. Nuclei exhibited regular outlines and had some heterochromatin clumps (Figs. 35 and 36).

\section{Morphometric results: \\ 1) Cell count morphometric analysis}

The results of statistical analysis showed significant decrease $(p<0.05)$ in myocyte number of adult HFD treated group (Ib) compared with adult control (Ia) and artichoke treated (Ic) groups. On the other hand, group Ic showed significant increase in myocyte number compared with group Ib but still significantly less in myocyte count than group Ia. In aged HFD treated group (IIb), there was significant decrease in the number of myocytes compared with both aged control (IIa) and artichoke (IIc) groups. Meanwhile, Group IIc had significant increase in myocyte number compared with other aged groups. All aged groups showed significant decrease in myocyte number compared with the corresponding adult groups (Table 1 and 
Figure 1').

\section{2) Cell diameter morphometric analysis}

In adult HFD treated group (Ib), statistical analysis showed significant increase in myocyte diameter compared with adult control (Ia) and artichoke treated (Ic) groups.
Aged HFD treated group (IIb) showed significant increase in the myocyte diameter compared with aged control (IIa) and artichoke (IIc) groups. Moreover, all aged groups showed significant decrease in myocyte diameter when compared with the corresponding adult groups (Table 2 and figure $2^{\prime}$ ).

Table 1: The mean \pm SD of cell count in the studied groups

\begin{tabular}{|c|c|c|c|c|}
\hline Age & Group name & Mean $\pm \mathrm{SD}$ & Range & P-value \\
\hline \multirow{3}{*}{ Adult groups } & Group Ia & $25 \pm 2.06$ & $20-29$ & \multirow{3}{*}{$0.000^{* * *}$} \\
\hline & Group Ib & $12.86 \pm 2.04$ & $9-16$ & \\
\hline & Group Ic & $18.58 \pm 2.09$ & $14-23$ & \\
\hline \multirow{3}{*}{ Aged groups } & Group IIa & $11.32 \pm 1.8$ & $9-15$ & \multirow{3}{*}{$0.000^{* * *}$} \\
\hline & Group IIb & $7.66 \pm 1.64$ & $5-11$ & \\
\hline & Group IIc & $17 \pm 1.57$ & $14-20$ & \\
\hline
\end{tabular}

Kruskal-Wallis Test

* Statistical significant difference $(P<0.05)$

Group Iavs.Group IIa: $0.000^{* * *}$, Group Ibvs.Group IIb: $0.000^{* * *}$, Group Icvs.Group IIc: $0.000^{* * *}$, (Mann-Whitney Test), Group Iavs Group Ib $0.000^{* * *}$ Group IIavs. Group IIb $0.000 * * *$, Group Iavs. Group Ic $0.000 * * *$ Group IIavs. Group IIc $0.000 * * *$, Group Ibvs.Group Ic $0.000 * * *$ Group IIbvs. Group IIc $0.000 * * *$

(ANOVA Test)

Table 2: The mean \pm SD of cell diameter $(\mu \mathrm{m})$ in the studied groups

\begin{tabular}{|c|c|c|c|c|}
\hline Age & Group name & Mean \pm SD & Range & P-value \\
\hline \multirow{3}{*}{ Adult groups } & Group Ia & $13.2 \pm 1.67$ & $9-15$ & \multirow{4}{*}{$0.000^{* * *}$} \\
\hline & Group Ib & $16.06 \pm 2.36$ & $12-23$ & \\
\hline & Group Ic & $12.86 \pm 1.71$ & $10-15$ & \\
\hline \multirow{3}{*}{ Aged groups } & Group IIa & $9.84 \pm 1.012$ & $8-12$ & \\
\hline & Group IIb & $14.16 \pm 1.59$ & $12-17$ & \multirow[t]{2}{*}{$0.000^{* * *}$} \\
\hline & Group IIc & $11.88 \pm 1.26$ & $10-15$ & \\
\hline
\end{tabular}

Kruskal-Wallis Test

* Statistical significant difference $(\mathrm{P}<0.05)$

Group Iavs.Group IIa: $0.000^{* * *}$, Group Ibvs.Group IIb: $0.000^{* * *}$, Group Icvs.Group IIc: $0.000^{* * *}$, (Mann-Whitney Test), Group Iavs. Group Ib $0.000^{* * *}$ Group IIavs. Group IIb $0.000 * * *$, Group Iavs. Group Ic $0.000 * * *$ Group IIavs. Group IIc $0.000^{* * *}$, Group Ibvs.Group Ic $0.000 * * *$ Group IIbvs. Group IIc $0.000 * * *$

(ANOVA Test) 


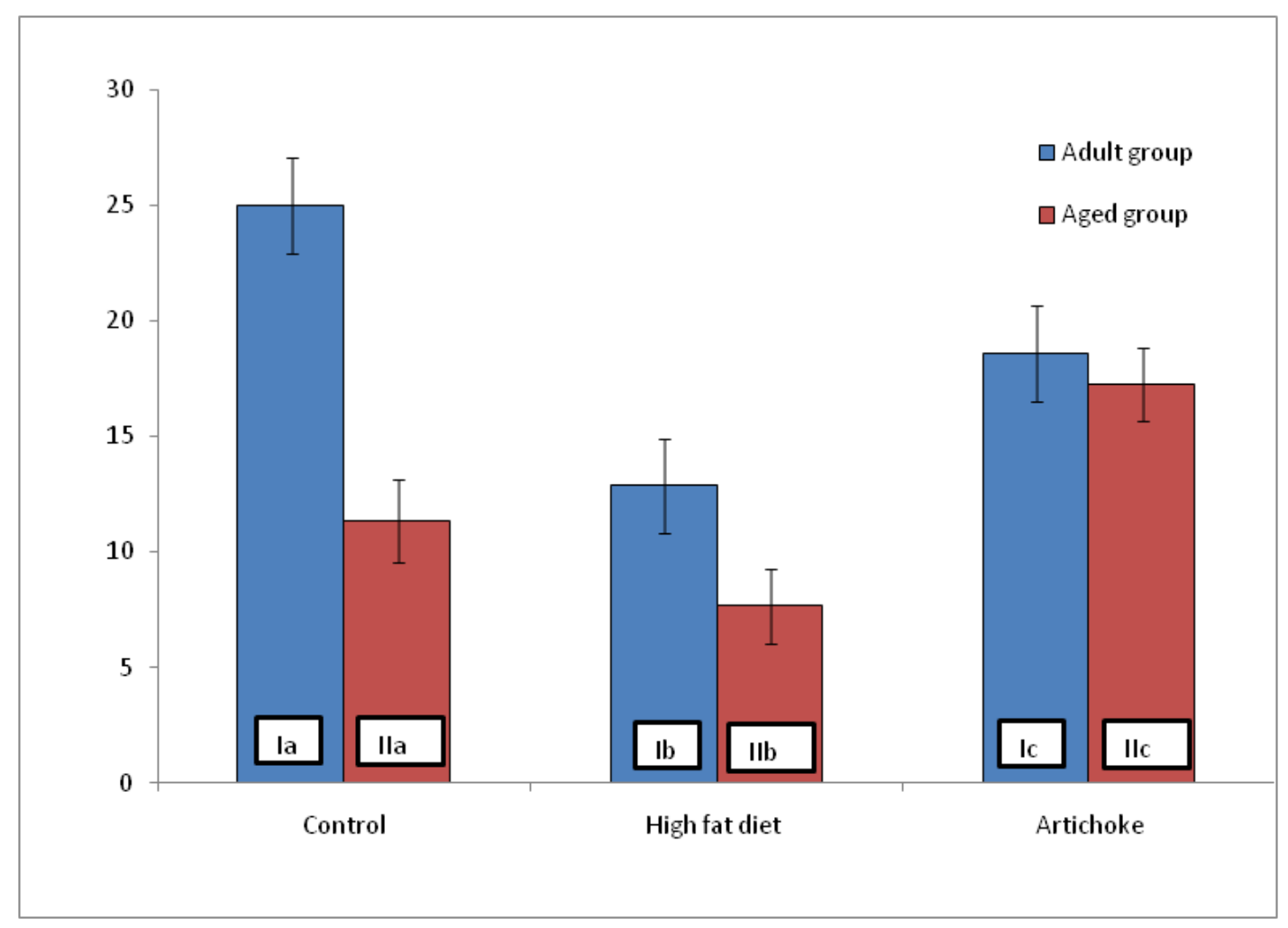

Fig. (1'): The mean $\pm \mathrm{SD}$ of myocyte countinall studied groups

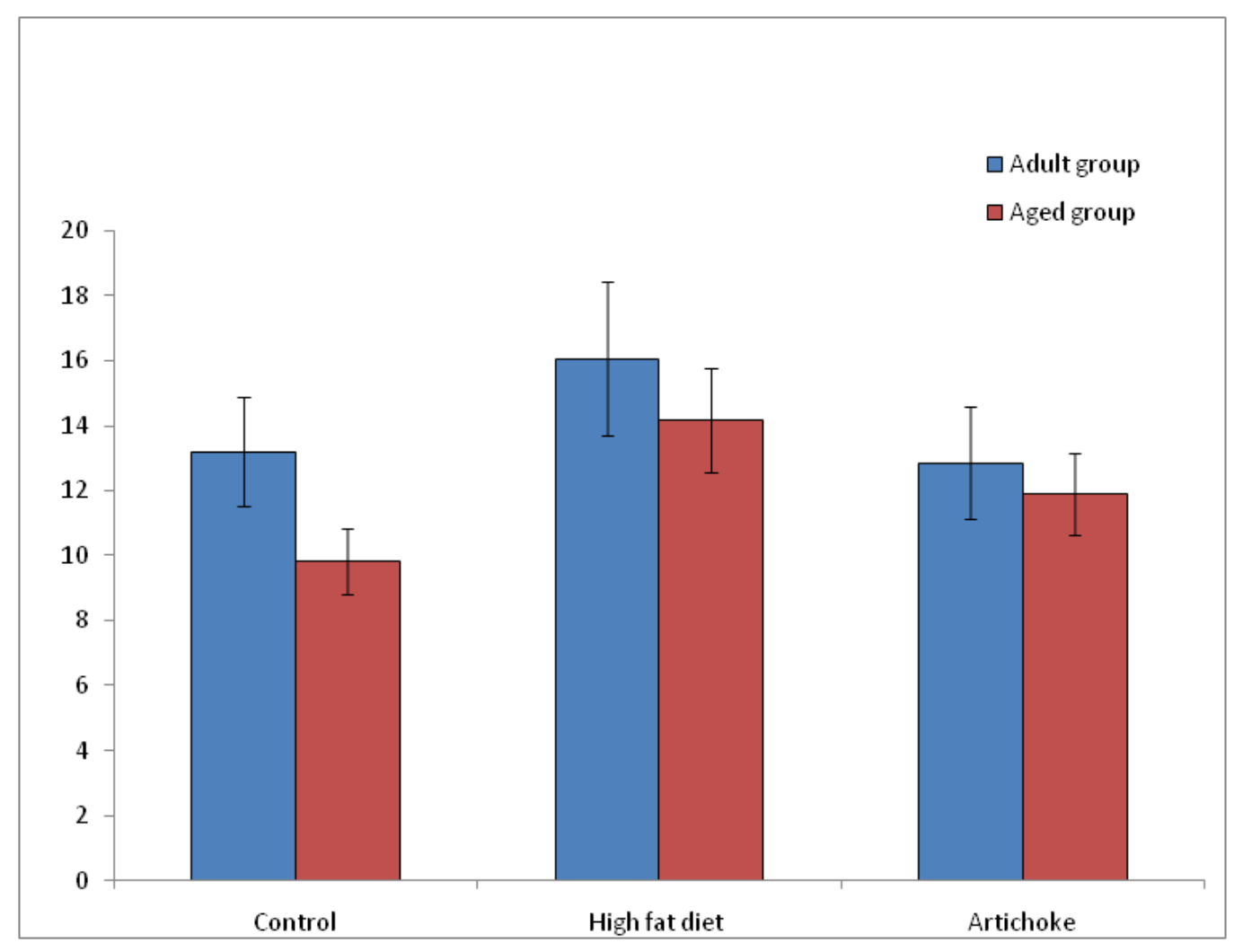

Fig. 2': The mean $\pm \mathrm{SD}$ of myocyte diameter $(\mu \mathrm{m})$ inall studied groups 


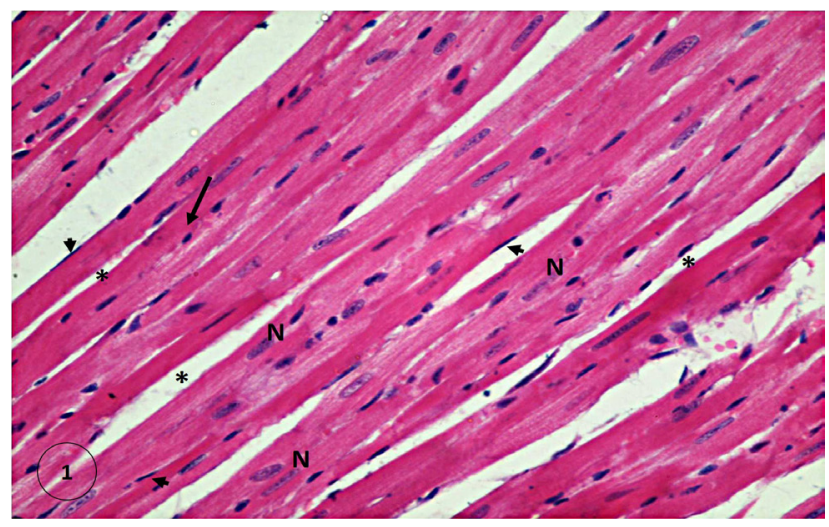

Fig. 1: A photomicrograph of longitudinal section of left ventricle of group Ia showing cardiac muscle fibers are branching cylindrical with central vesicular oval nuclei $(\mathrm{N})$ and highly acidophilic sarcoplasm (arrow). Minor spaces of endomysium are seen among muscle fibers $(*)$. Small population of fibroblasts with flat dense nuclei are observed (arrow heads) (H \& E X400).

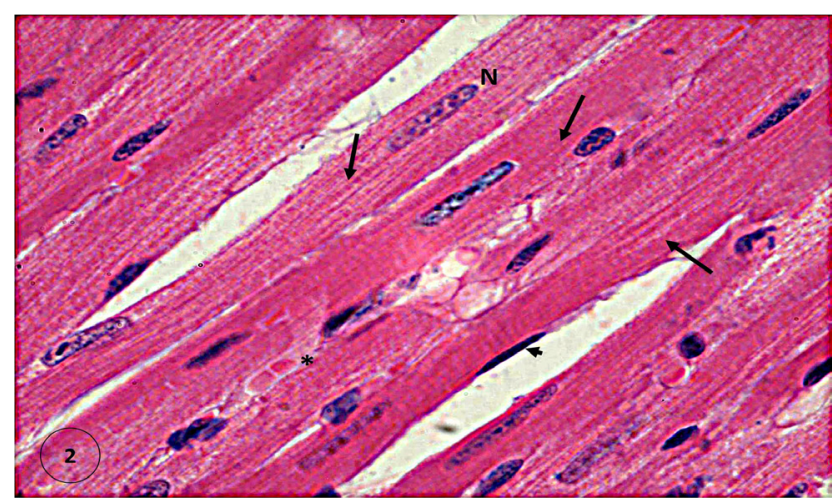

Fig. 2: A magnified part of longitudinal section of left ventricle of group Ia showing anastomosing muscle fibers with central elongated vesicular nuclei $(\mathrm{N})$ and transversely striated and highly acidophilic sarcoplasm (arrows). Endomysium is seen among the muscle fibers containing blood capillaries (*). Notice; flat dense nuclei of few fibroblasts (arrowhead) (H \& E X1000).

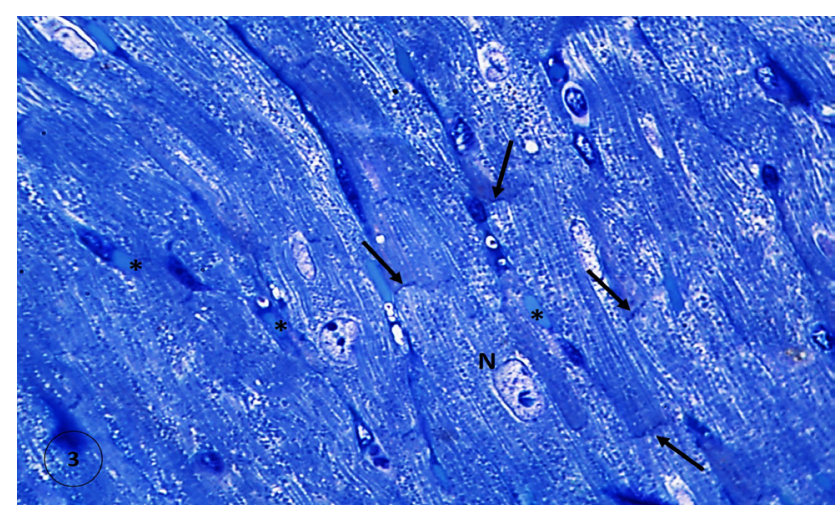

Fig. 3: A photomicrograph of semithin section of left ventricle of group Ia showing branching cardiac muscle fibers that anastomose forming continuous syncytium. Cross striations of sarcoplasmbearing central oval vesicular nuclei $(\mathrm{N})$ is noticed. Intercalated discs (arrows) are visible among adjacent myocytes and many blood capillaries $\left(^{*}\right)$ are seen in narrow spaces of endomysium (toluidine blue $\mathrm{x} 1000$ ).

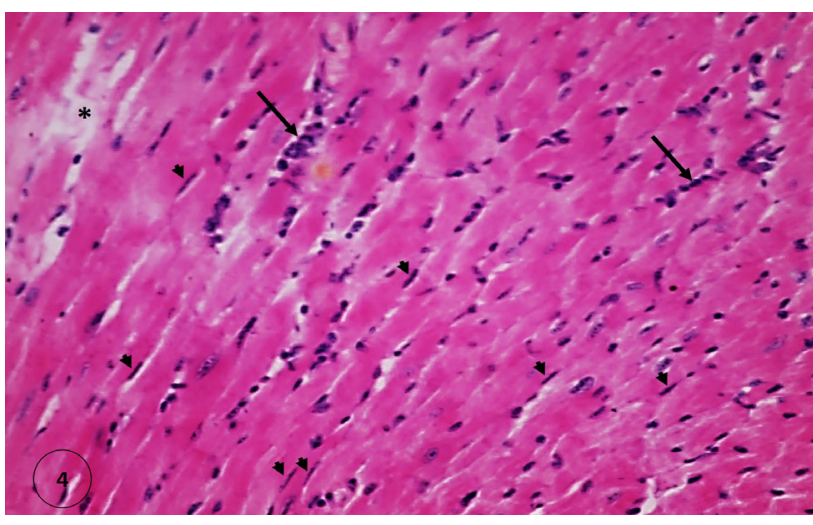

Fig. 4: A photomicrograph of longitudinal section of left ventricle of group Ib showing small foci of muscle fiber loss $\left(^{*}\right)$ and local inflammatory cell infiltrate among myofibers (arrows). Loss of sarcoplasmic cross striations is noticed. There are many fibroblasts are seen among myofibers compared with group Ia (arrowheads) (H \& E x400).

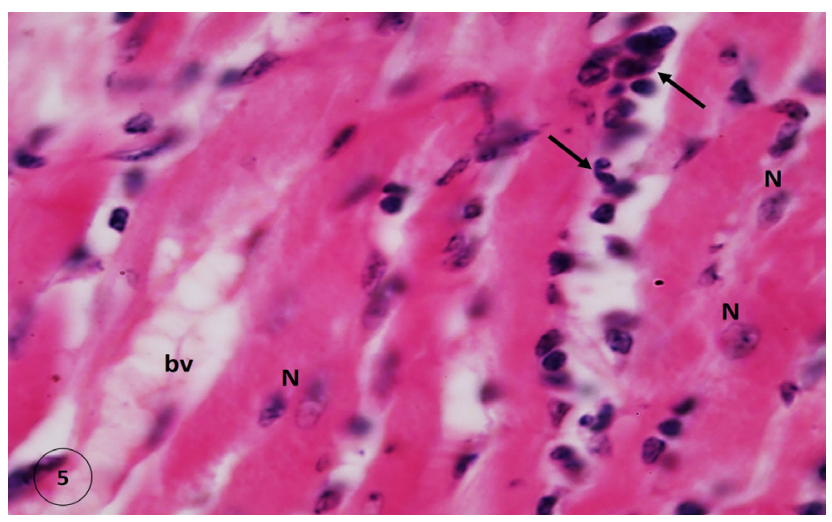

Fig. 5: A magnified part of longitudinal section of left ventricle of group Ib showing lost sarcoplasmic cross striations, congested blood vessels (bv) and inflammatory cell infiltration among muscle fibers (arrows). Nuclei of some myocytes appear rounded or shrunken (N) (H \& E x 1000).

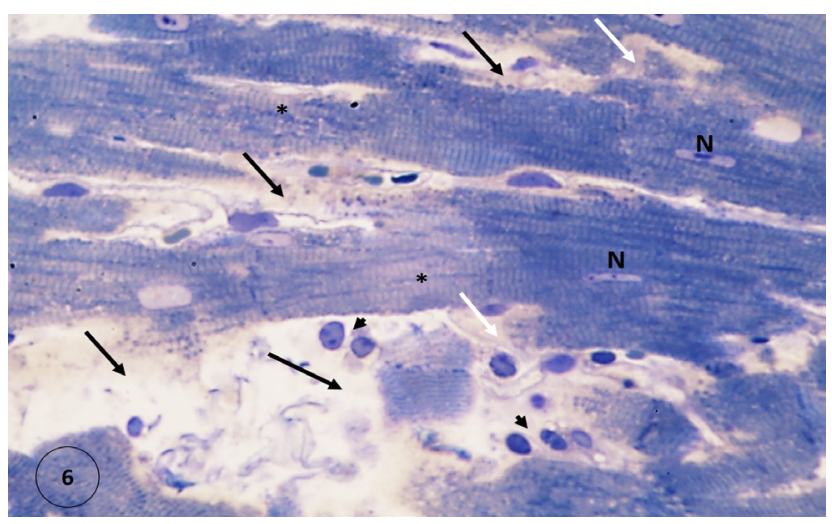

Fig. 6: A photomicrograph of semithin section of cardiac muscle fibers of left ventricle of group Ib showing foci of cardiac myofiber loss (white arrows) and other areas have pale sarcoplasm (*) with obvious widening of intercellular spaces and encroachment of CT replacing parts of the cells (black arrows). Some nuclei appear shrunken $(\mathrm{N})$. Some inflammatory cells are also visible (arrowheads) residing endomysium (toluidine blue x1000). 


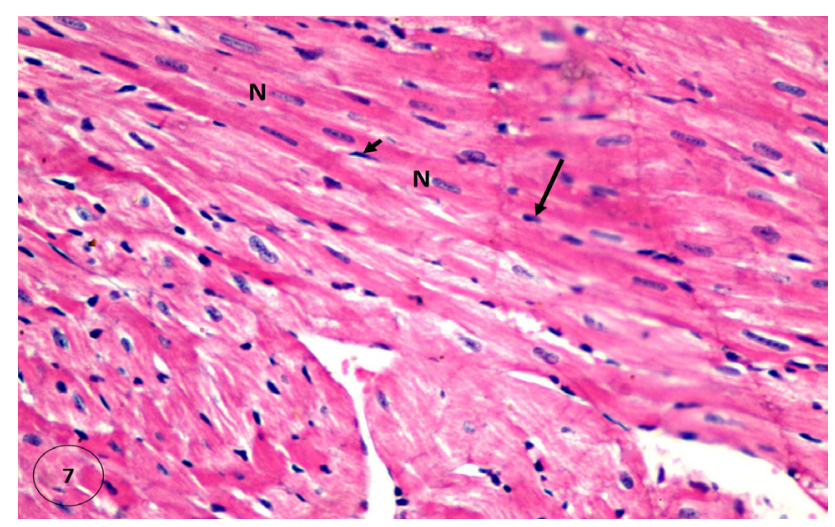

Fig. 7: A photomicrograph of longitudinal section of left ventricle of group Ic showing cardiac myocytes are improved compared with group Ib. No foci of muscle fiber loss or inflammatory cell infiltration can be detected. Nuclei of many myocytes appear more or less normal $(\mathrm{N})$ but few still appear dense (arrow). Fibroblast population appear similar to group Ia (arrowhead) (H \& E X400).

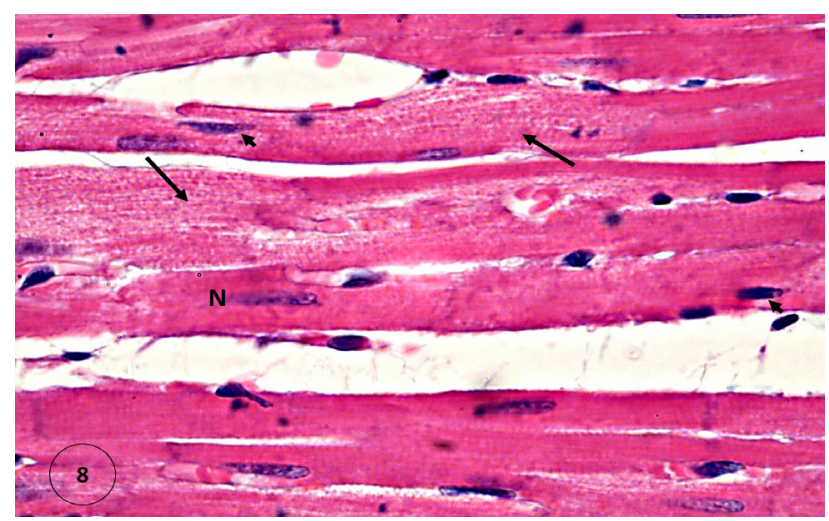

Fig. 8: A magnified part of longitudinal section of left ventricle of group Ic showing sarcoplasmic cross striations appear more or less similar to control group (arrows). Most nuclei (N) are oval and vesicular while few of them are still affected (arrowheads) (H \& E X1000).

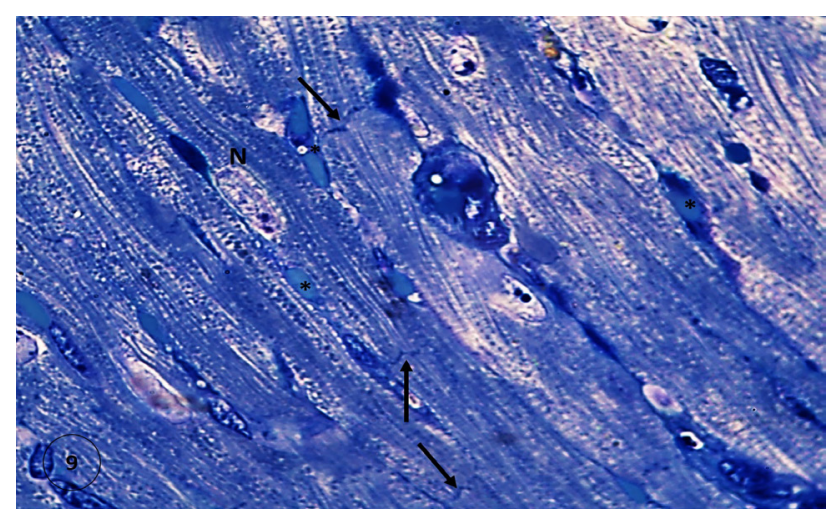

Fig. 9: A photomicrograph of semithin section of cardiac muscle fibers of left ventricle of group Ic showing muscle fibers appear more or less normal. They are closely packed with minor endomysial spaces in between. Most nuclei seem normal $(\mathrm{N})$ and cross striations of sarcoplasm are obvious. intercalated discs among fibers are visible (arrows). Blood capillaries mostly look normal $(*)$ (toluidine blue $\mathrm{x} 1000)$.

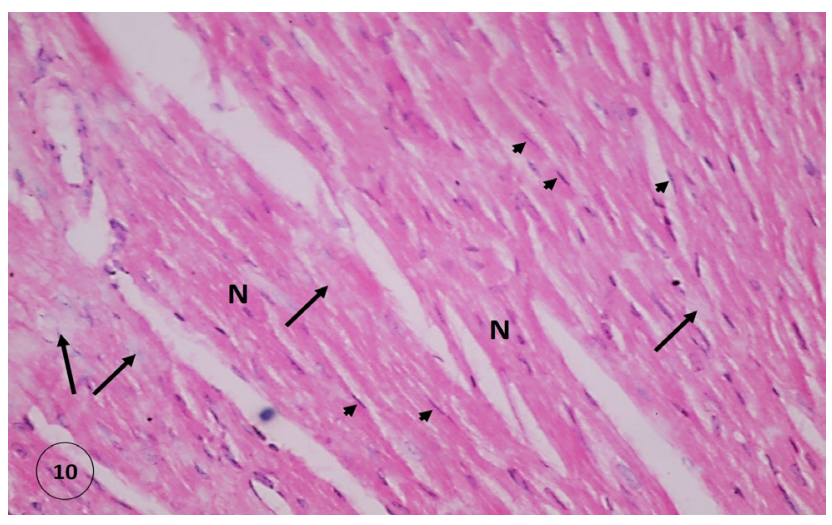

Fig. 10: A photomicrograph of longitudinal section of left ventricle of group IIa showing cardiac myocytes are loosely packed with widening of intercellular spaces compared with group Ia. Sarcoplasm of most fibers appear pale acidophilic and degenerated with obvious loss of its cross striations (arrows). Nuclei are dense and shrunken $(\mathrm{N})$. Unlike group Ia, many flat dense nuclei of fibroblasts are observed (arrow heads) (H \& E x400).

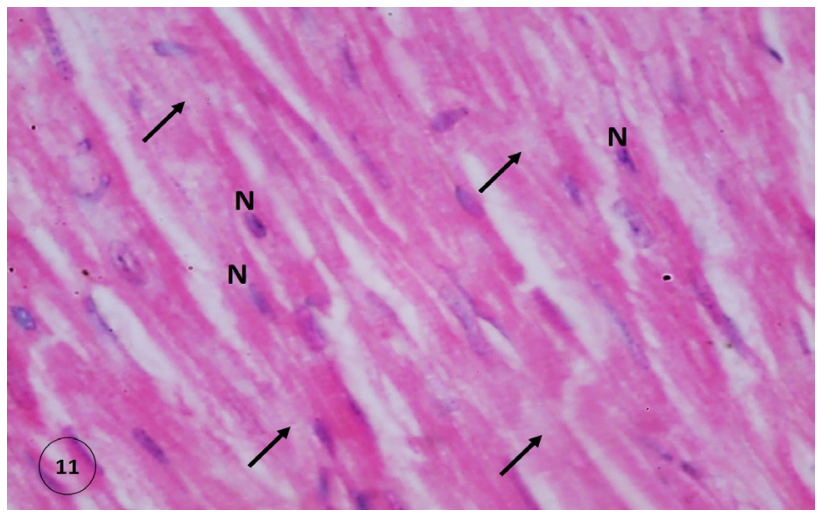

Fig. 11: A magnified part of longitudinal section of left ventricle of group IIa showing most muscle fibers have shrunken dense nuclei $(\mathrm{N})$. Sarcoplasm of most cells is pale, degenerated and lacks its cross striations (arrows)

(H \& E x1000).

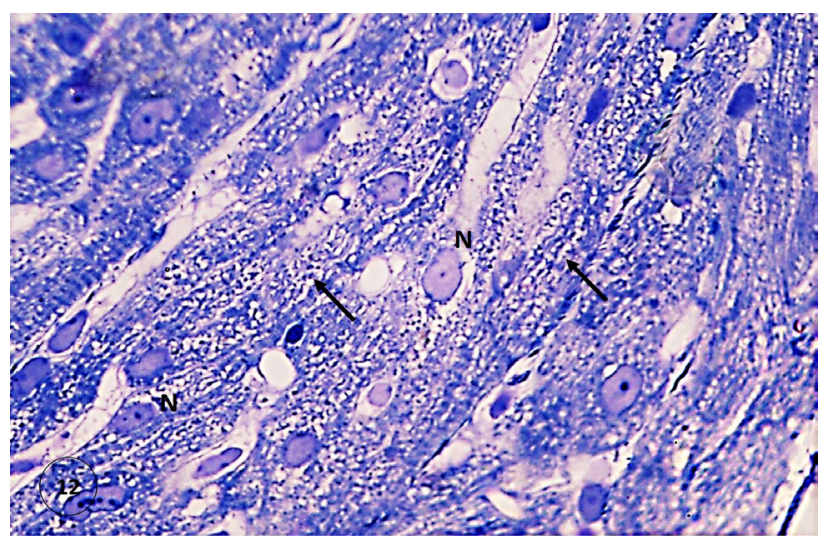

Fig. 12: A photomicrograph of semithin sections of left ventricle of group IIa showing disturbed architecture of cardiac tissue. Degeneration and lack of cross striations of sarcoplasm (arrows) and pyknosis of nuclei $(\mathrm{N})$ of most cells are observed (toluidine blue $\mathrm{x} 1000)$. 


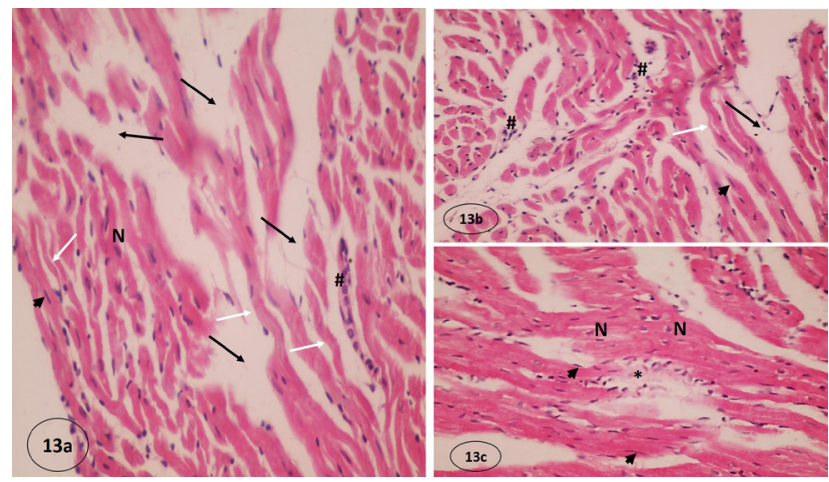

Fig. 13: A photomicrograph of longitudinal section of left ventricle of group IIb showing cardiac myocyte damage is more exaggerated than groups IIa and Ib. Many myocytes are lost with marked widening of intercellular spaces (black arrows) that harbor some inflammatory cells (\#). Some fibers have wavy corrugated appearance (white arrows) 13a\&b. Focal areas of muscle fiber loss $(*)$ are also observed 13c. Nuclei are dense and shrunken (N). Many fibroblasts with flat dense nuclei (arrow heads) are observed apparently more abundant than those noticed in sections of all other groups ( $\mathrm{H} \& \mathrm{E} \times 400)$.

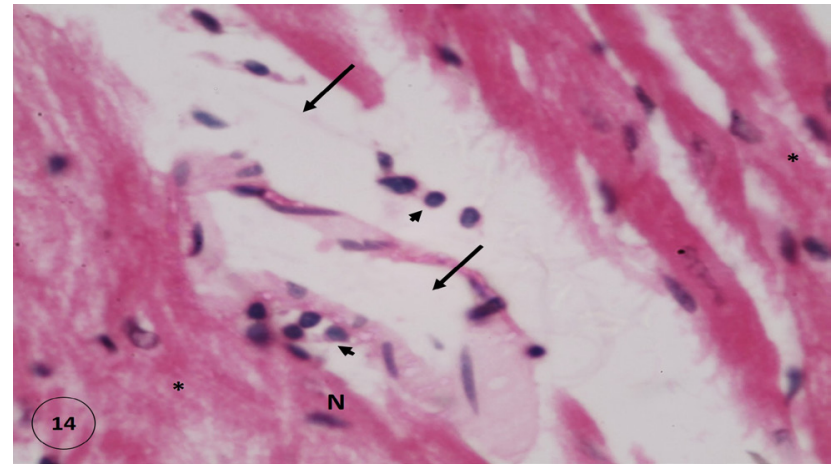

Fig. 14: A magnified part of left ventricle of group IIb showing marked disruption of architecture and more myofiber loss and lysis compared with groups IIa\&Ib, leaving very wide intercellular spaces (arrows). Sarcoplasm of remaining muscle fibers appear pale, disintegrated and lost its cross striation $\left({ }^{*}\right)$ and the nuclei are shrunken $(\mathrm{N})$. Notice; intercellular space containing some inflammatory cell infiltrate (arrow heads) (H \& E x1000).

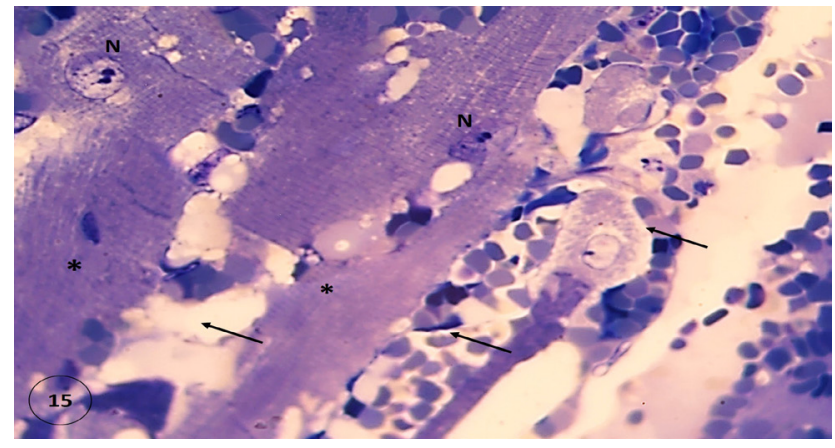

Fig. 15: A photomicrograph of semithin sections of left ventricle of group IIb showing muscle fibers have disintegrated sarcoplasm with obvious loss of cytoplasmic striations $(*)$. Their nuclei are pyknotic $(\mathrm{N})$. Marked widening of intercellular spaces, vasodilation and congestion of blood vessels and inflammatory cell infiltrate are noticed (arrows) (toluidine blue x1000).

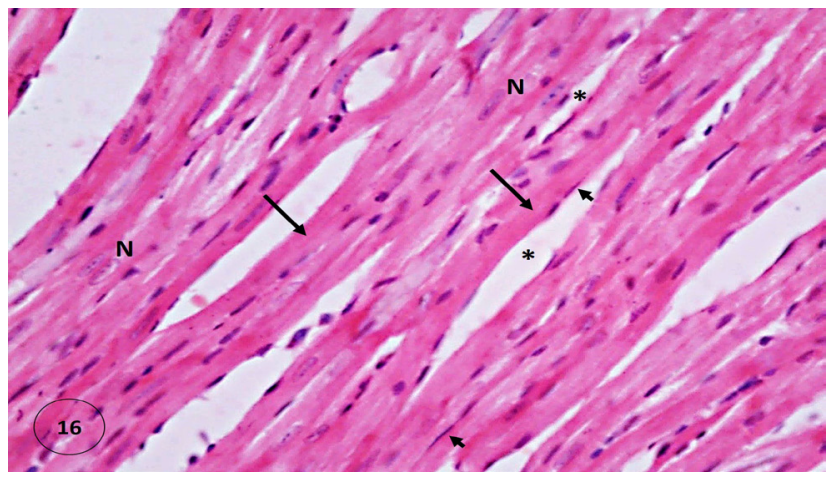

Fig. 16: A photomicrograph of longitudinal section of left ventricle of group IIc showing cardiac muscle fibers are obviously improved compared with other aged groups. They appear branched and cylindrical more closely paced with narrower intercellular spaces $(*)$ and having more acidophilic cytoplasm (arrows). Fewer population of fibroblasts (arrow heads) are noticed compared with other aged groups. No corrugation or focal degeneration or local inflammation is observed. Some fibers have vesicular and oval nuclei (N) (H \& E x400).

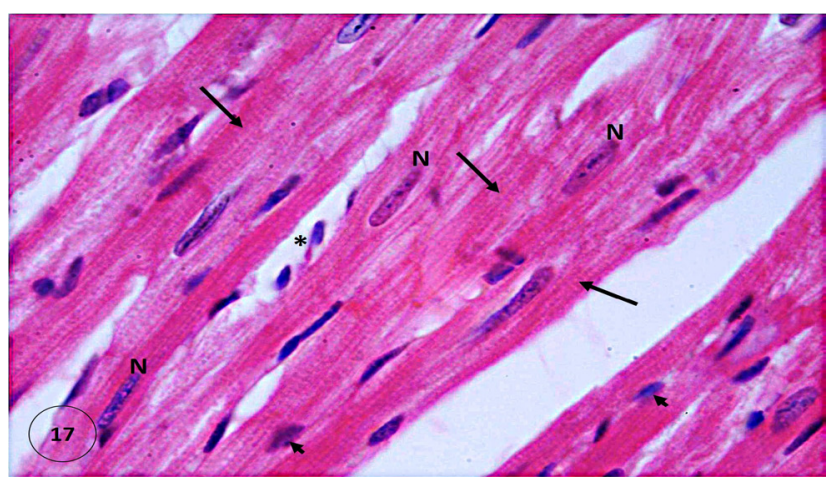

Fig. 17: A magnified part of left ventricle of group IIc showing cardiac myocytes are improved compared with other aged groups. Sarcoplasm appears more acidophilic and have cross striations (arrows). Also, some nuclei appear normal (N) while others are still affected (arrowheads). Small intercellular spaces are observed among muscle fibers $(*)$ (H \& E x 1000).

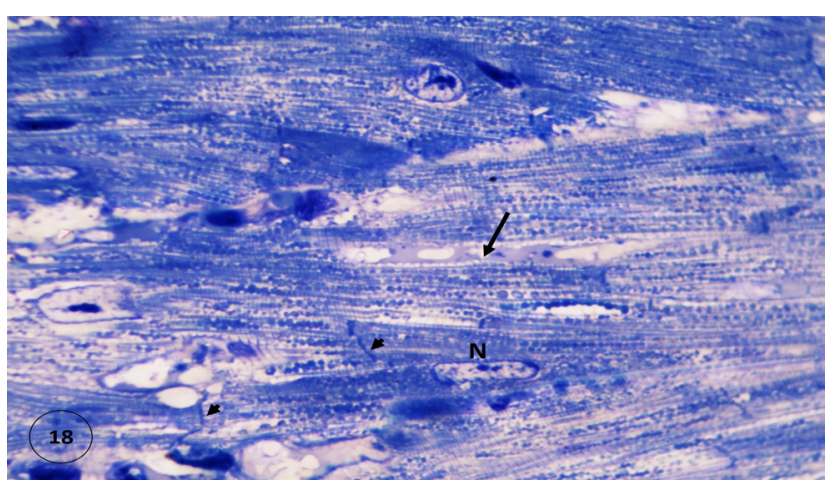

Fig. 18: A photomicrograph of longitudinal section of left ventricle of group IIc showing cardiac myocytes are much improved than other aged groups. Sarcoplasm shows cross striations and some nuclei are Improved (N). No blood congestion and much smaller intercellular spaces is observed among myocytes (arrow). Notice intercalated discs among myocytes (arrow heads)

(toluidine blue x1000). 


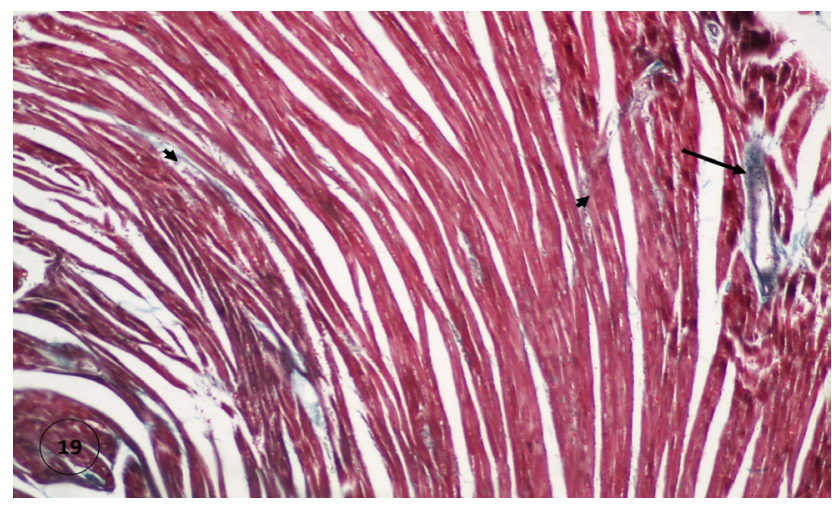

Fig. 19: A photomicrograph of longitudinal section of left ventricle of group Ia showing scanty collagen fibers are seen around blood vessels (arrow) and among myocytes (arrow heads)

(Masson trichrome X400)

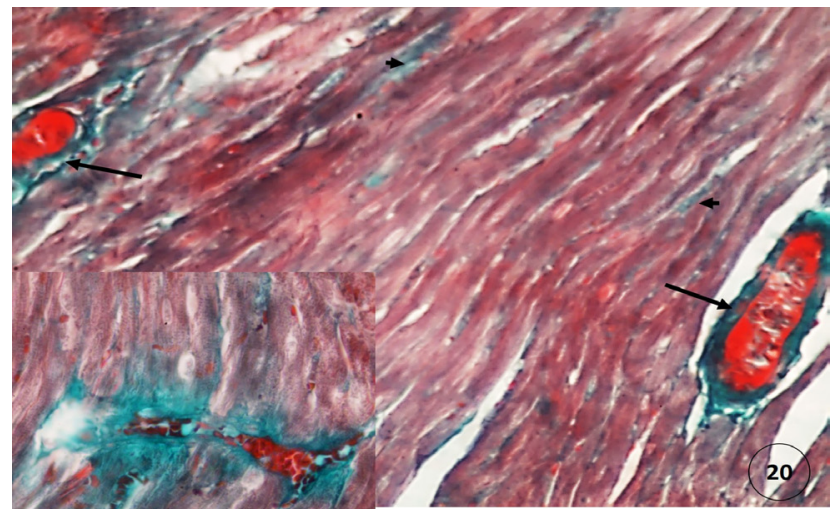

Fig. 20: A photomicrograph of longitudinal section of left ventricle of group Ib showing obvious increase in the amount of collagen fibers noticed around congested blood vessels (arrows) and among myocytes (arrow heads) compared with group Ia(Masson Trichrome stain x400). Inset: show remarkable amount of collagen fibers around blood vessels and replacing adjacent myocytes

(Masson trichrome X1000).

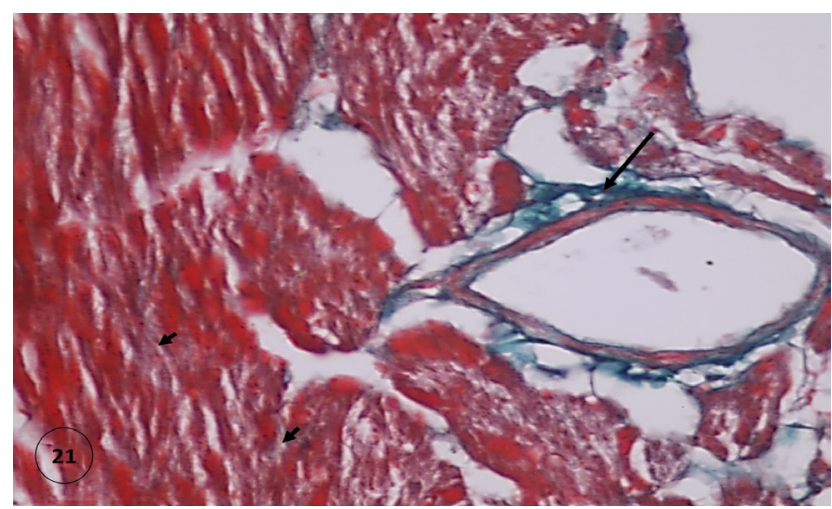

Fig. 21: A photomicrograph of longitudinal section of left ventricle of group Ic showing decrease in the amount of collagen fibers around blood vessels compared with group Ib (arrow) and almost appear normal among muscle fibers (arrow heads)

(Masson trichrome X400).

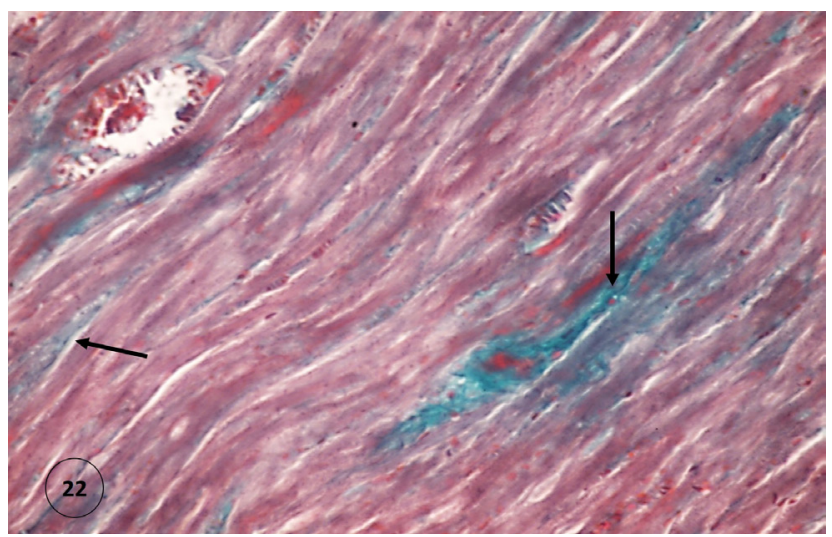

Fig. 22: A photomicrograph of longitudinal section of left ventricle of group IIa showing greater amount of collagen fibers is observed among myofibers (arrows) compared with group Ia

(Masson trichrome X400).

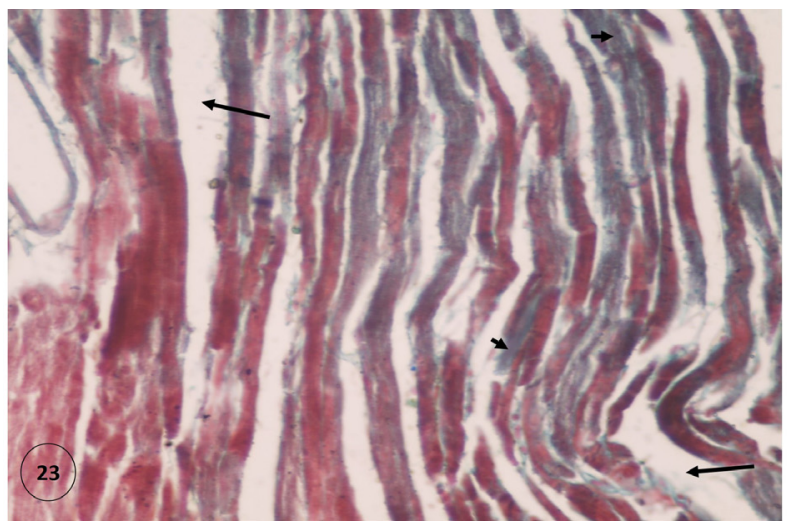

Fig. 23: A photomicrograph of longitudinal section of left ventricle of group IIb showing increased amount of collagen fibers compared with group IIa that replacing many muscle fibers (arrowheads). Notice; marked widening of intercellular spaces (arrows) (Masson trichrome X400).

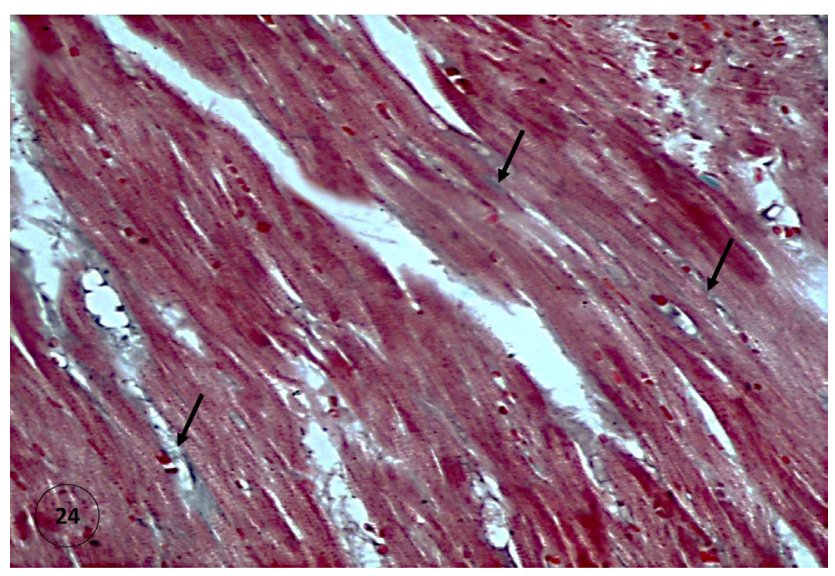

Fig. 24: A photomicrograph of longitudinal section of left ventricle of group IIc showing decreased amount of collagen fibers among muscle fibers compared with other aged groups (arrows) (Masson trichrome X400). 

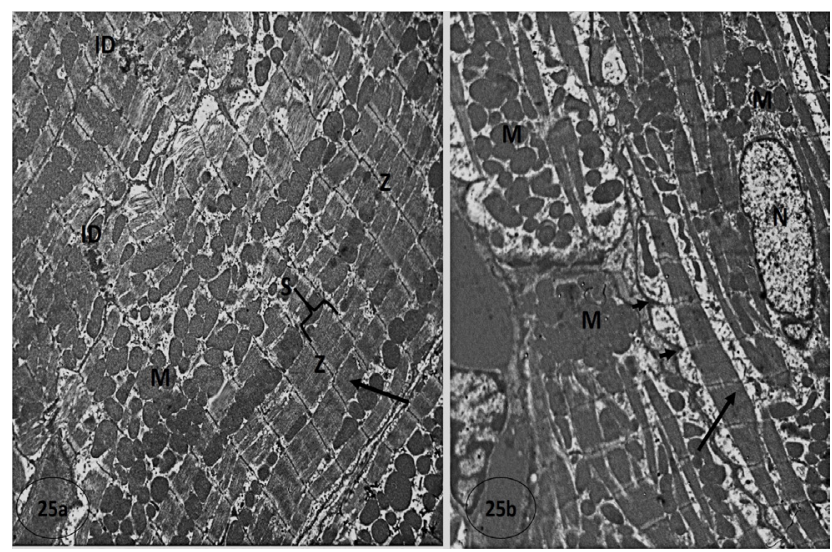

Fig: 25: An electron micrograph of cardiac muscle fibers of group Ia showing parallel arrays of cylindrical myofibrils (arrows) occupying most of the sarcoplasm. Each myofibril consists of repeated sarcomeres (S) separated at $\mathrm{Z}$ lines $(\mathrm{Z})$. Abundant mitochondria (M) with intact densely packed cristae are seen among myofibrils and near nucleus. Intercalated discs (ID) are clearly seen among adjacent cells. Nucleus (N) is oval and euchromatic. Invaginations of sarcolemma are also observed (arrow heads) (X3600).

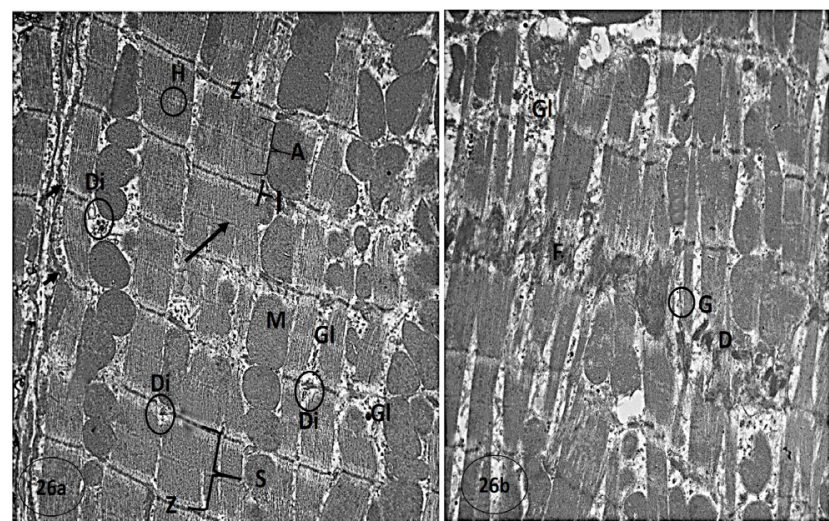

Fig. 26: An electron micrograph of cardiac myocytes of group Ia showing each sarcomere (S) is limited by two $\mathrm{Z}$ lines $(\mathrm{Z})$ and consists of central dark A band (A) and two peripheral halves of light I bands (I). A narrow light $\mathrm{H}$ zone $(\mathrm{H})$ is seen in the center of $\mathrm{A}$ band and is bisected by $\mathrm{M}$ line ((arrow). Abundant large mitochondria (M) are observed among and parallel to myofibrils. Mitochondria appear oval and rounded in shape with densely packed intact cristae. Sarcolemma form invaginations (origin of $\mathrm{T}$ tubules) opposite $\mathrm{Z}$ lines (arrowheads). Diads (Di) are seen at the level of $Z$ lines and glycogen granules $(\mathrm{Gl})$ are seen among myofibrils. Notice; Intercalated disc is observed at the site of $\mathrm{Z}$ line connecting adjacent myocytes and has 3 parts; fascia adherents $(F)$, desmosome (D) and gap junction $(G)$ in (26b)

(X7200).

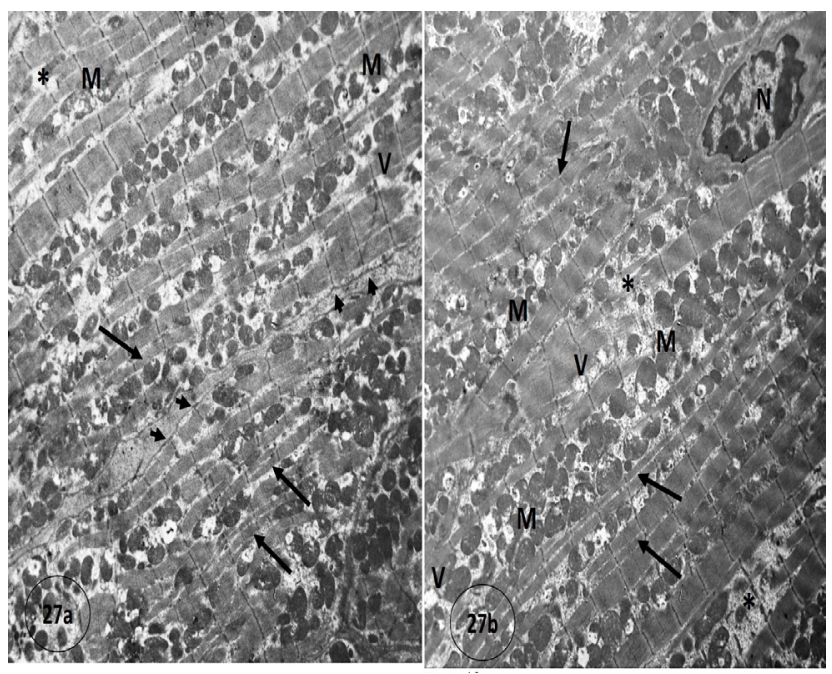

Fig. 27: An electron micrograph of cardiac muscle fibers of group $\mathrm{Ib}$ showing intramyocellular accumulation of fat vacuoles (V). Many mitochondria have partially damaged cristae (M). Most myofibrils appear thin and split (arrows). Some foci of myofibrillar degeneration with disruption of $Z$ lines $(*)$ are noticed. Nucleus (N) is shrunken with irregular outline and contains many heterochromatin clumps. Sarcolemma appear smooth and lacks most of its invaginations at $\mathrm{Z}$ line (arrowheads)

(X3600).

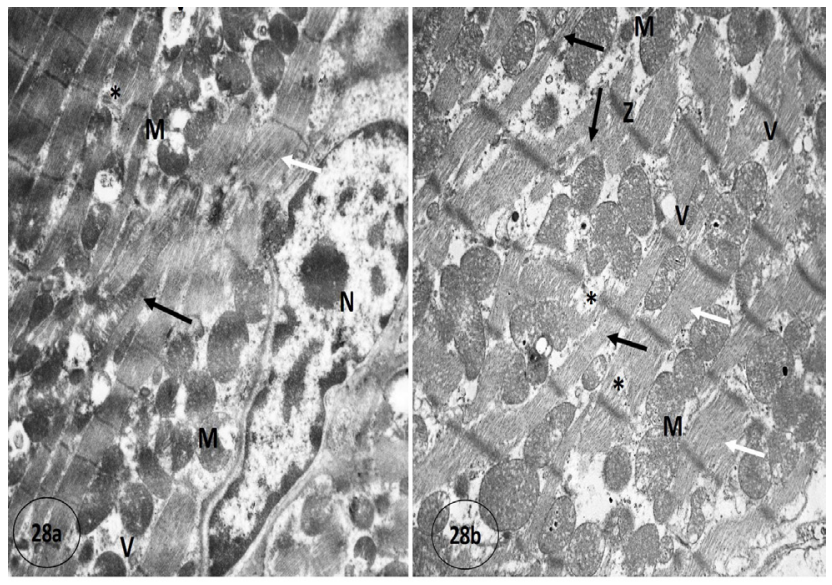

Fig. 28: An electron micrograph of cardiac muscle fibers of group $\mathrm{Ib}$ showing intermyofibillar accumulation of lipid vacuoles (V). Mitochondria have partially destroyed cristae (M). Some myofibrils appear thin and split (black arrows). Foci of myofibrillarlysis with disruption of $\mathrm{Z}$ line $(*)$ are also noticed. $\mathrm{A}$ and I bands are not clearly seen (white arrows) and $\mathrm{Z}$ lines are either disrupted or appear irregular and hazy (Z). Nucleus is shrunken, have many heterochromatin clumps and exhibits irregular outline with dilated perinuclear cisternae (N) (X7200). 


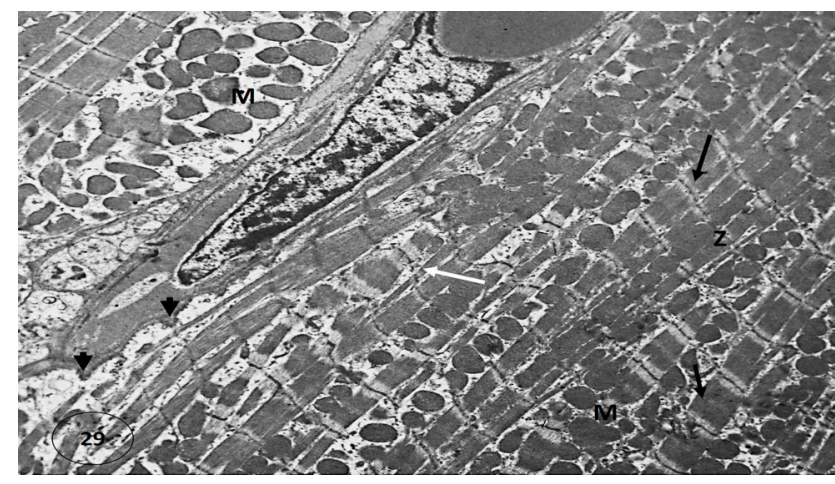

Fig. 29: An electron micrograph of cardiac muscle fibers of group Ic showing most myofibrils are improved (black arrows) compared with group $\mathrm{Ib}$. No intramyocellular fat vacuolation or myofibrillar degeneration is observed but few myofibrils still appear thin (white arrow). Successive sarcomeres and Z lines (Z) appear normal. Mitochondria have intact cristae(M). Sarcolemmal Invaginations at Z lines are preserved (arrowheads) (X3600).

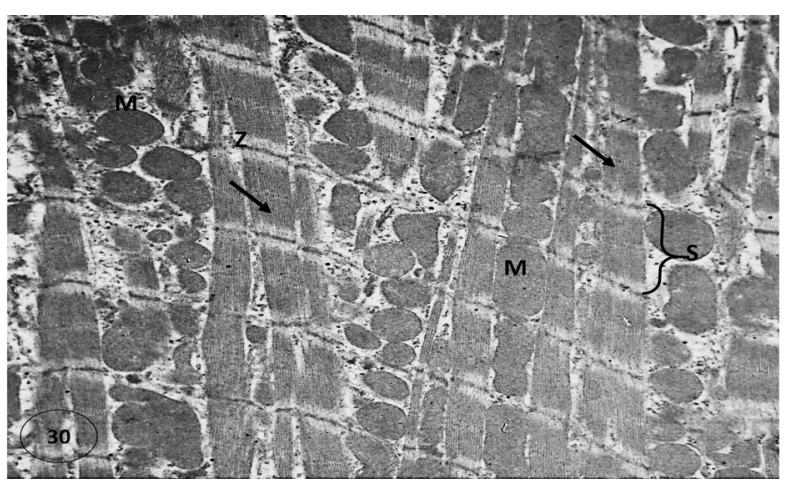

Fig. 30: An electron micrograph of cardiac muscle fibers of group Ic showing normal appearance of most myofibrils (arrows) that have regular arrangement of sarcomeres (S) and intact $Z$ lines (Z). Mitochondria have intact densely packed crista (M).No lipid vacuoles or focal degeneration are noticed (X7200).

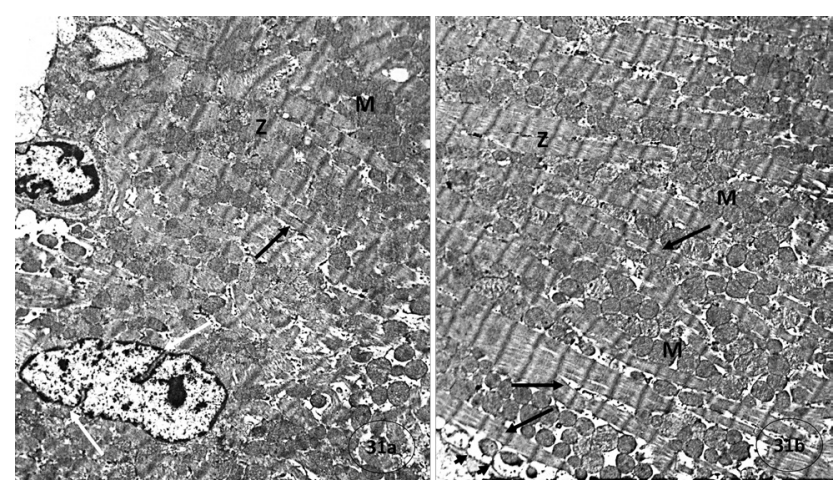

Fig. 31: An electron micrograph of cardiac muscle fibers of group IIa showing myofibrils are disorganized, thin, and their myofilaments are split and loosely packed (black arrows) and Z lines appear hazy (Z). Compared with group Ia, most sarcoplasm is apparently occupied with mitochondria with less number of myofibrils. Many mitochondria appear large with intact closely packed cristae (M). Nucleus (N) has irregular and deeply indented membrane (white arrow) with some heterochromatin clumps. Invaginations of sarcolemma are observed (arrowheads) (X3600).

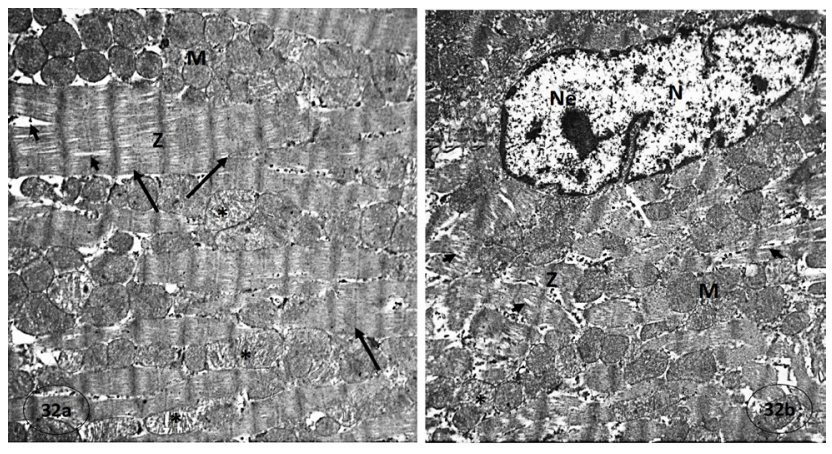

Fig. 32: An electron micrograph of cardiac muscle fibers of group IIa showing some myofilaments are split (arrow heads), sarcomeres have hazy $\mathrm{Z}$ lines $(\mathrm{Z})$ and $\mathrm{A}$ bands appear as narrow lighter central areas (black arrows). Many mitochondria (M) are large with intact densely packed cristae occupying most sarcoplasm while others have partially damaged cristae $\left(^{*}\right)$. Nucleus has prominent nucleolus $(\mathrm{Ne})$, irregular and indented outline (white arrow) and contains some heterochromatin clumps (X7200).

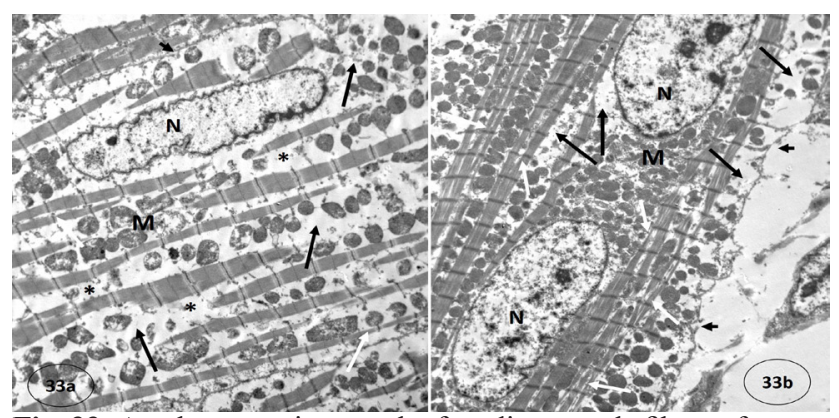

Fig. 33: An electron micrograph of cardiac muscle fibers of group IIb showing complete lysis of many myofibrils leaving empty spaces with increased intermyfibrillar spaces $(*)$. The remaining myofibrils are thin and split (white arrows). Many mitochondria are completely damaged leaving empty spaces (black arrows). Some mitochondria remain in sarcoplasm and mostly appear damaged (M). Sarcolemma is disrupted and loses almost its invaginations (arrow heads). Nuclei (N) have irregular outlines (X3600).

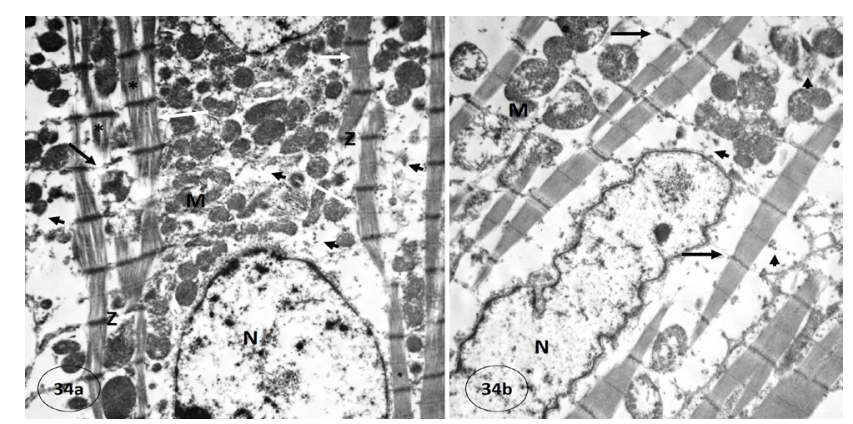

Fig. 34: An electron micrograph of cardiac muscle fibers of group IIb showing fragmentation and complete lysis of myofibrils with increased intermyofibrillar spaces (black arrows). In 34a Sarcomeres are disintegrated; myofilaments are split and degenerated (*), A, H and I bands are not clearly detected (white arrows) and $\mathrm{Z}$ lines $(\mathrm{Z})$ are disrupted. Many mitochondria are completely damaged leaving empty spaces (arrowheads) but others are partially destroyed (M). Nucleus (N) is indented and has irregular outline (X7200). 


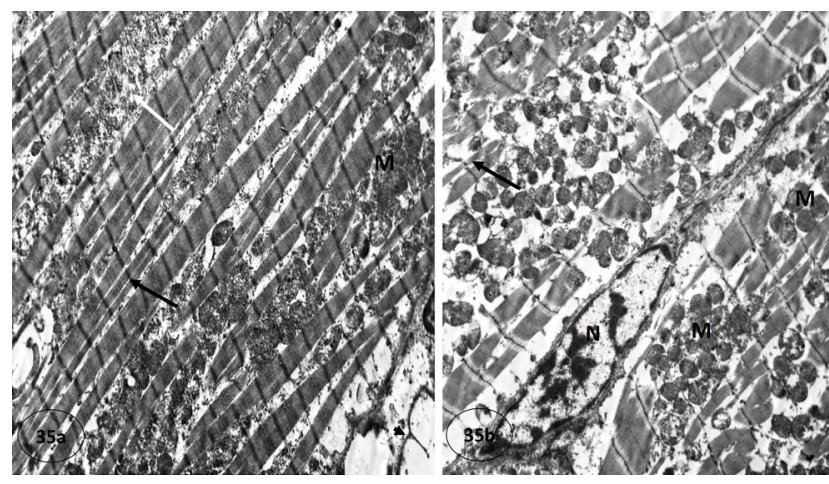

Fig. 35: An electron micrograph of cardiac muscle fibers of group IIc showing regular parallel arrays of myofibrils with smaller interfibrillar spaces compared with group IIb but still some myofibrils are thin (black arrows). Some mitochondria appear normal (M) but others are damaged (white arrows). Nucleus (N) exhibits regular outline and has scatted heterochromatin clumps. In 35a; invaginations of sarcolemma are observed (arrow head) (X3600).

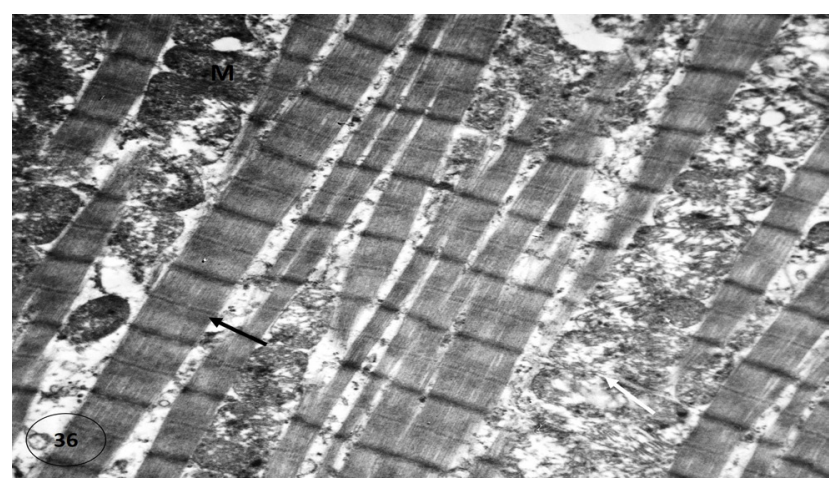

Fig. 36: An electron micrograph of cardiac muscle fibers of group IIc showing cylindrical myofibrils with regular sarcomeres, tightly packed myofilaments, A and Ib and are clearly demarcated but A band appear narrow like group IIa (black arrow). Unlike other aged groups, myofibrils apparently fill most of sarcoplasm. Some mitochondria have damaged cristae (white arrow) while others appear with intact cristae (M) (X7200).

\section{DISCUSSION}

Previous efforts have described aging related cardiac muscle changes ${ }^{[17]}$. Some researchers also have demonstrated lipotoxic effects of HFD on cardiac muscle function ${ }^{[18]}$ but such studies are still limited. The coexistence of aging and obesity has been associated with serous cardiac morbidity, which is mostly fatal ${ }^{[4]}$. However, the study of associated cardiac structural alterations in these cases are not clear and need further investigations. Up to our knowledge, so far, the present study is the first detailed histological, morphometric and ultrastructural investigation that reporting high fat induced structural changes in cardiac of adult mice, in addition to, addressing and comparing the effect of adiposity in aged cardiac muscle. Moreover, the current study evaluated the efficacy of concomitant treatment of artichoke in mitigating HFD induced cardiac myopathy in both adult and aged mice. In the current study, mice model was used as commonly done in previous cardiovascular researches. Mice are considered an ideal model in the current work especially in studying aging groups, as they do not develop hypertension with aging or senescence ${ }^{[17]}$. This allowed us to evaluate aging related cardiac changes independent of vascular effects. Moreover, it has been reported that cardiac aging in mice closely recapitulates human aging process ${ }^{[19]}$.

In the current study, cardiac myocytes of adult HFD treated group showed remarkable structural changes and disturbance of architecture. Intramyocellular accumulation of lipid droplets, partial destruction of mitochondrial cristae, Pyknosis and shrinkage of nuclei, and loss of sarcolemmal invaginations of $\mathrm{T}$ tubule system were obviously reported. Loss of sarcoplasmic cross striations, consistent with myofibillaralterations seen by electron microscope, was also noticed. Increased fibrous tissue content of cardiac tissue and inflammatory cell infiltrate were also observed. There were diverse myofibrillar changes were recorded including thinning and splitting of myofibrils, focal myofibrillar lysis and disruption of the organization and normal appearance of sarcomeres. Statistically, myocytes of adult HFD treated mice showed significant increase in myocyte diameter associated with significant decrease in myocyte number compared with other adult groups.

Our findings are consistent with previous reports of intramyocellular accumulation of lipid droplets ${ }^{[20]}$ and mitochondrial damage and cristolysis ${ }^{[18]}$ noticed in hyperlipidemic rat cardiac muscle. In the current work, the observed cardiac muscle damage can be attributed to serious effects of hyperlipidemia that can be evoked at molecular and cellular levels. In this regard, previous efforts have revealed that high fat intake can lead to abnormal and inappropriate intramyocellular deposition of triglyceride in cardiac muscle, such condition is referred to be as cardiac steatosis ${ }^{[21]}$. Overaccumulation of triglyceride is associated with increased intramyocellular expression of lipogenicenzymes resulting in increased esterification and impaired oxidation of the raised pool of fatty acids ${ }^{[22]}$. Subsequently, the intracellular pool of fatty acyl-coenzyme A enlarges, providing substrate for non-oxidative metabolic pathways that lead to oxidative stress, inflammation, apoptosis, fibrosis and cellular dysfunction ${ }^{[18,23,24]}$.

Interestingly, the current statistical analysis of adult HFD group showed significant decrease in myocyte number concomitant with significant increase in myocyte diameter, which indicates cardiac muscle loss and hypertrophy respectively. The present results are similar to recent reporton myocardium of obese mouse ${ }^{[25]}$. As explained in previous studies, lipotoxicity is characterized by both cardiomyocytes loss as a consequence of increased apoptosis with fibrotic tissue replacing lost cells and hypertrophy of the remaining myocytes ${ }^{[23,26]}$. In fact, myocyte loss is associated with diverse cardiac dysfunction 
mainly decrease in contractility, arrhythmia, wall dilatation. Cardiac arrhythmia can be attributed to disruption in gap junctions and electrical coupling as a result of lost myocytes $^{[27]}$. In this regard, we reported obvious impairment of myofibrils and their constituting myofilaments in adult hyperlipidemic mice, which represent the contractile machinery of cardiac muscle. Accordingly, we can add that at subcellular level, the observed myofibrillar loss and disruption can also contribute to obesity associated cardiac contractility disorders. Earlier efforts recorded impaired myocardial contractility and function in hyperlipidemic rats. The authors owed the observed cardiac dysfunction to activation of apoptotic pathway "lipoapoptosis" secondary to increased ceramide level, a mediator of apoptosis, with subsequent increased expression of nitric oxide synthase 'iNOS' and overproduction of nitric oxide "NO" resulting in impaired cardiac contractility and function ${ }^{[20]}$.

In the present work, a remarkable finding in myocardium of adult hyperlipidemic mice is the increase in amount of collagen and fibroblast pool, which indicates cardiac fibrosis. Fibrosis ultimately contributes to more deterioration and loss of cardiac function secondary to obesity. Zhou YT and his colleagues $(2000)^{[20]}$ reported significant increase in the ratio of hydroxyproline amount compared to the total protein content of cardiac tissue in adult obese rats, which is consistent with our record. It was concluded that cardiac steatosis, like hepatic and insular steatosis, is ultimately followed by progressive fibrosis ${ }^{[20]}$.

In the current study, obvious changes were detected in aged cardiac muscle compared with adult myocardium. There was significant decrease in cardiac myocyte number and diameter compared with adult control group. Myofibers became loosely packed with widening of intercellular spaces. Lack of sarcoplasmic cross striations, apparent increase in fibroblast population and increase collagen fiber content were noticed. At ultrastructural level, many large mitochondria, some of them with partially damaged cristae, were occupying most of sarcoplasm compared with apparently scanty number of myofibrils. Thinning and splitting of myofibrils, and disruption of sarcomeres were reported but sarcolemmal $\mathrm{T}$ tubules invaginations were still preserved. Indentation, shrinkage and pyknosis of nuclei was also noticed. Similar observations were previously reported in aged myocardium in both humans and rats ${ }^{[28]}$. In the current work, we observed widening of intermyofiber spaces, obvious increase and encroachment of fibrous tissue that replacing adjacent myocytes associated with significant decrease in myocyte numbers of aged myocardium. Previous histological analysis has revealed that aging is associated with progressive cardiomyocytes loss due to both apoptotic and necrotic cell death ${ }^{[29]}$. Furthermore, Anna B and Nikolas G (2011) ${ }^{[30]}$ have demonstrated that aging is characterized by continuous and progressive circuit of cardiac fibrosis and myocyte loss. They hypothesized that the thickening of the extracellular matrix occur around aged cardiomyocytes results in mismatch between supply and demand of nutrients, and leads to myocyte death. Interstitial fibroblasts respond to signals released by dying cardiomyocytes by synthesizing new matrix aimed at replacing the damaged cells resulting in more myocyte loss. Interestingly, previous researches on aged myocardium have used the term cardiac sarcopenia to describe the aging related continuous decline in myocyte numbers whichassociated with reduced cardiac function mainly contractile performance ${ }^{[31]}$. Our observations of myocyte loss are also in accordance with these reports. Moreover, at ultrastructure level and unlike adult control myocardium, we reported apparently scanty abnormal myofibrils within the aged cardiac myocytes compared with more abundant pool of enlarged mitochondria that occupy most sarcoplasm. In fact, our observation of obvious disturbance in contractile elements of aged myocytes in addition to their reduced numbers can both contribute to aging related reduced cardiac function. Collectively, for the first time, we can suggest that, the term aging related sarcopenia should not only used to refer to and to describe the aging related decrease in myocyte numbers but should also include the accompanied decrease and disruption in myofibrils and contractile machinery within aged myocytes seen at ultrastructure level.

In the present study, aged myocytes showed significant decrease in myocyte diameter compared with adult group, which is opposite to previous reports of myocyte hypertrophy in aged myocardium ${ }^{[30,31]}$. Actually, our record showed that all aged groups had significant decrease in both cell diameter and number when compared with the corresponding adult groups. In this regard, our finding of apparently abnormal large abundant mitochondriawhich fill most sarcoplasm compared with scanty myofibrilsmay provide an evidence of the decrease in myocyte diameter. Aged cardiac myocytes seem under stress due to reduction in their number, and size, and contractile elements so they need more energy and effort trying to maintain their normal function, thereby there was abnormal compensatory increase in size and number of mitochondria in aged cardiac myocytes. Unfortunately, mitochondria is vulnerable to mitochondrial oxidative stress with aging that is associated with increased production of reactive oxygen species "ROS". This could explain the noticeable partial cristolysis of some mitochondria in the current work. This fact has been confirmed by previous report of increased production of superoxide radicals from mitochondria extracted from aging rat hearts ${ }^{[32]}$. In addition, another study on mice has documented increased mitochondrial DNA mutations and deletions, and has concluded that the production of mitochondrial ROS contributes to cardiac myocyte damage with aging ${ }^{[32]}$.

An important finding in our study of aged myocardium, is the apparent increase in collagen fibers and fibroblast pool, which indicates myocardial fibrosis. Earlier efforts have documented increased collagen deposition and aging associated myocardial fibrosis ${ }^{[30,31]}$. Indeed, the 
occurrence of myocardial fibrosis in addition to senescence related sarcopenia could contribute to more progressive impairment in cardiac function that can progress to cardiac failure as previously concluded ${ }^{[33]}$. In fact, several factors and mechanisms have been involved in aging related cardiac fibrosis as explained by Anna B and Nikolas G $(2011)^{[30]}$. A primary factor in this process is the reduction in the proteolytic activity of "matrix metalloproteinases (MMPs) expression by cardiac fibroblasts" that lead to attenuation of matrix-degrading pathways and subsequent excessive collagen accumulation in the aging heart. Another important mechanism is aging associated phenotypic transition of fibroblasts into myofibroblasts, the key effector cells in fibrotic state by increasing collagen synthesis. Aging associated oxidative stress and release of reactive oxygen species" mitochondrial ROS" have been also suggested to have important role in cardiac fibrosis. ROS has been reported to have fibrogenic actions. The end result of all these mechanisms are perivascular, endomysial and perimysialfibrosis ${ }^{[30]}$.

Interestingly, the most striking findings noticed in the current work, were related to the impact of HFD on aged myocardium. Indeed, up to our knowledge, the current study is the first reporting of the impact of HFD on aged myocardium at myocellular level. We reported that the coexistence of adiposity has exaggerated the aging induced myocardium changes. We noticed maximum damage and disruption of architecture of myocardium in aged HFD treated group when compared with the adult HFD treated and control aged mice. Statistically, there were significant decrease in myocyte number compared with other aged groups and adult HFD group. The myocyte diameter was significantly increased compared with other aged groups but significantly smaller than that of adult HFD group. The profound myocyte loss was associated with marked widening of intermyofiber space, corrugation, focal degeneration and loss of cross striations of myocytes. In addition, local inflammatory cell infiltrate, shrinkage, irregularity and pyknosis of nuclei, extensive deposition and displacement of connective tissue of adjacent myocytes and marked increase in fibroblast population were observed. At ultrastructural level, there was pronounced myofibrillar lysis and degeneration accompanied by simultaneous complete destruction of many mitochondria so many regions of sarcoplasm appeared empty. The remaining myofibrils were split and thin and sarcomere arrangement and appearance were obviously disrupted. Taken together, these observations provide evidence that the coexistence of aging and high fat diet synergistically accentuate and aggravate myocardial damage. In other words, we can hypothesize that coexistence of obesity and aging together is highly serious situation that can lead to profound and progressive deterioration in cardiac function, which ultimately can lead to death due to extensive myocardial damage. In this regard and in accordance with our observation and conclusion, previous reports have documented that the coupling of aging and obesity factors contributes to increase the production of $\operatorname{ROS}^{[34]}$. Other efforts have added that the aging process enhances the metabolic and vascular effects evoked by HFD through augmenting oxidative stress and increase the production of $\operatorname{ROS}^{[35]}$. Furthermore, a recent study in skeletal muscle showed loss of myonuclei and myofiber area in HFD aged mice and the authors hypothesized that high-fat feeding in conjunction with aging generates signals that induce myofiber atrophy, most probably through ubiquitin proteasome system ${ }^{[36]}$. In fact, further investigations are still needed and highly recommended to define the underlying mechanisms behind the synergistic destructive effect of both aging and obesity on myocardium that we noticed in the current study.

In the current study, a very relevant shared finding in both adult and aged HFD treated groups was the presence of agglomerates of endomysial inflammatory cell infiltrate which could be attributed to oxidative stress and the elevated lipid peroxidation evoked by abnormal accumulation of fat in myocardium. In consistent with that, similar observation was reported in the hepatic tissue of young and old mice fed on high fat $\operatorname{diet}^{[37]}$. The authors concluded that HFD could induce a state of steatohepatitis. They added that the abnormal accumulation of fat in liver evokes elevated lipid peroxidation. Reactive agents generated from lipid peroxidation induce inflammatory cytokines, inflammation and subsequent fibrosis. These agents also cause more cell damage that amplifies oxidative stress effects ${ }^{[37]}$.

Artichoke (Cynarascolymus) is a well-known herbal plant frequently used in Mediterranean countries and is one of the traditional components of diets in some longlived countries ${ }^{[38]}$. Recently, artichoke attracted the interest of many researchers who tried to demonstrate its beneficial effect as a natural lipid lowering agent in some organs ${ }^{[8,38,39]}$. In the current study, we tried for the first time to assess the possible cardioprotective role of artichoke against obesity associated cardiac damage in both adult and aged mice. Our observations demonstrated obvious improvement in the architecture of cardiac tissue in both young and old mice. In both artichoke treated adult and aged myocardium, myocytes appeared closely packed with narrow intercellular spaces. Sarcoplasmic cross striations were preserved with no foci of myofiber loss, corrugation or inflammation. Many nuclei appeared normal. In addition, the amount of collagen fiber were obviously decreased and almost appeared like normal. At ultrastructural level, most myofibrils and sarcomeres exhibited normal appearance and organization. Compared with other aged groups, myofibrils appeared occupying most of sarcoplasm. Mitochondria were improved, more obvious in adult mice. Statistically in both adult and aged artichoke groups, there were significant increase in the number of cardiac myocytes associated with significant decrease in cell size compared with the corresponding HFD groups. Indeed, the noticeable improvement of myocardium in the current study reinforces previous reports done on other organs. 
Artichoke was found to be effectively and significantly decrease the level of cholesterol and triglyceride and also have hepatoprotective effect in both human and anima ${ }^{[38]}$. According to the current observations, we can suggest that artichoke has both powerful hypolipidemic and antiaging properties on cardiac muscle, which could be attributed to its antioxidant properties. In accordance with that, earlier investigations have demonstrated that artichoke has powerful antioxidant effects ${ }^{[8]}$. It has been found to be highly effective in decreasing the production of reactive oxygen species, the oxidation of low-density lipoproteins, lipid peroxidation and protein oxidation, in addition to scavenging free radicals before they can damage cells ${ }^{[40]}$. In this regard, it is found that artichoke is highly rich in many antioxidant ingredients such as mono- and dicaffeoylquinic acid (cynarin and chlorogenic acid), caffeic acid and flavonoids including the glycosides luteolin-7- $\beta$ rutinoside (scolymoside), luteolin-7- $\beta$-D-glucoside, and luteolin-4- $\beta$-D-glucoside with chlorogenic acid is reported as the most active antioxidant ingredient ${ }^{[41]}$. Actually, recent efforts have investigated the possible underlying mechanisms behind the hypolipidemic nature of artichoke ${ }^{[8,42]}$. It has been found that artichoke can interact with Hydroxy-Methyl-Glutaryl-Coenzyme A (HMG-CoA) reductase, as well as with liver sterol regulatory element-binding proteins (SREBPs) and acetylCoA C-acetyltransferase (ACAT), leading to reduce cholesterollevel ${ }^{[38]}$. Moreover, artichoke might reduce hypercholesterolemia by increasing the fecal excretion of bile acids and also by directly influencing biosynthesis of cholesterol ${ }^{[38,43]}$. Indeed, the current reporting of obvious and remarkable improvement in the myocardium of both adult and aged artichoke groups may give very promising insightsfor using artichoke as natural hypolipidemic and antiaging agent that is effective in protecting and/or treating obesity and/or aging associated myocardial diseases.

\section{CONCLUSION}

Our findings demonstrated that aged myocardium is more susceptible to and has more extensive lipotoxicdamagecompared with adult one. Lipotoxicinsults includedisruption of powerhouse and myofibrillar contractile machinery, thereby, could impair cardiac function. There could be synergistic cross talk betweenobesity and aging that leads to profound cardiac damage. Further investigations are highly recommended to explain the underlying mechanisms in case of such coupling. Concomitant treatment of artichoke is markedly improved myocardial damage in both adult and aged mice so it could be used as an effective cardioprotectiveagainst hyperlipidemia and aging insults.

\section{CONFLICT OF INTEREST}

There are no conflicts of interest

\section{REFERENCES}

1. Al Nohair S. Obesity in Gulf Countries. Inter J Health Sci (2014); 8 (1): 80-83.

2. Catapano AL, Graham I, De Backer G, Wiklund O, Chapman M. J, Drexel H, Hoes, AW, Jennings CS, Landmesser U, Pedersen TR, Reiner Z, Riccardi G, Taskinen MR, Tokgozoglu L, Verschuren WM, Vlachopoulos C, Wood DA and Zamorano JL. 2016 ESC/EAS Guidelines for the Management of Dyslipidaemias: The Task Force for the Management of Dyslipidaemias of the European Society of Cardiology (ESC) and European Atherosclerosis Society (EAS) Developed with the special contribution of the European Association for Cardiovascular Prevention and Rehabilitation (EACPR). Atherosclerosis (2016); 253:281-344.

3. Ouwens DM, Sell H, Greulich S, and Eckel J. The role of epicardial and perivascular adipose tissue in the pathophysiology of cardiovascular disease. J Cell Mol Med (2010); 14: 2223-2234.

4. Jura $M$ and Kozak LP. Obesity and related consequences to ageing. AGE (2016); 38: 23.

5. Kirkland JL. Translating advances from the basic biology of aging into clinical application. ExpGerontol (2013); 48(1):1-5.

6. Cicero AF and Colletti A. Role of phytochemicals in the management of metabolic syndrome. Phytomedicine (2016); 23:1134-44.

7. Pirro M, Vetrani C, Bianchi C, Mannarino MR, Bernini $\mathrm{F}$ and Rivellese A A. Joint position statement on "Nutraceuticals for the treatment of hypercholesterolemia" of the Italian Society of Diabetology (SID) and of the Italian Society for the Study of Arteriosclerosis (SISA). NutrMetabCardiovasc Dis (2017); 27:2-17.

8. Sahebkara A, Pirrob M, Banachc M, Mikhailidise DP, Atkinf SL, and Cicero AF. Lipid-lowering activity of artichoke extracts: A systematic review and meta-analysis. Crit Rev Food SciNutr (2018); 58 (15): 2549-2556.

9. D’AntuonoI, Carola A, Sena LM, Linsalata V, Cardinali A, Logrieco AF, Colucci MG and Apone F. Artichoke Polyphenols Produce Skin Anti-Age Effects by Improving Endothelial Cell Integrity and Functionality. Molecules (2018); 23:2729.

10. Ishihara A, Ito A, Sakai K, Watanabe S, Kobayashi 
T, and Okuyama H.Dietary high-linoleate safflower oil is not hypocholesterolemic in aged mice after a long-term feeding--comparison with lard, perilla oil and fish oil. Biol Pharm Bull(1995); 18(4): 485-90.

11. Isoda K, Kamezawa Y, Ayaori M, Kusuhara M, Tada N and Ohsuzu F. Osteopontin Transgenic Mice Fed a High-Cholesterol Diet Develop Early Fatty-Streak Lesions. Circulation (2003); 107:679-681.

12. Küskü-Kiraz Z, Mehmetçik G, Dogru-Abbasoglu $\mathrm{S}$, and Uysal M. Artichoke leaf extract reduces oxidative stress and lipoprotein dyshomeostasis in rats fed on high cholesterol diet. Phytother Res (2010); 24(4):565-70.

13. Bancroft JD, and Layton C. Theory and practice of histological techniques.7th ed.: Churchill Livingstone of Elsevier, Philadelphia; (2013). 172-214

14. Hyat MA. Chemical fixation. In: Principles and techniques of electron microscopy: biological applications. 4th ed. Edinburg, UK: Cambridge University Press (2000); 485.

15. Lin J, Lopez EF, Jin Y, Remmen HV, Bauch T, Han HC, and Lindsey ML. Age related cardiac muscle sarcopenia: Combining experimental and mathematical modeling to identify mechanisms. ExpGerontol (2008); 43(4): 296-306.

16. Gudadhe DR, Talhar SS, Bokariya P, Shende MR, and Tarnekar AM. Histomorphometric demonstration of cardiotoxic effects of aspartame on mice. Iosr J Pharm (2013); 3(2): 30-33.

17. Batkai S, Rajesh M, Mukhopadhyay P, Hasko G, Liaudet L, Cravatt BF, Csiszar A, Ungvari ZI, and Pacher P. Decreased age-related cardiac dysfunction, myocardial nitrative stress, inflammatory gene expression and apoptosis in mice lacking fatty acid amide hydrolase. Am J Physiol Heart CircPhysiol (2007); 293:H909-918.

18. Ouwens DM, Boer C, Fodor M, Galan P, Heine RJ, Maassen JA and Diamant M. Cardiac dysfunction induced by high-fat diet is associated with altered myocardial insulin signaling in rats. Diabetologia (2005); 48: 1229-1237.

19. Dai DF, Santana LF, Vermulst M, Tomazela DM, Emond MJ, MacCoss MJ, Gollahon K, Martin GM, Loeb LA, Ladiges WC and Rabinovitch PS. Overexpression of catalase targeted to mitochondria attenuates murine cardiac aging. Circulation (2009); 119:2789-97.

20. Zhou YT, Grayburn P, Karim A, Shimabukuro M, Higa M, Baetens D, Orci L and Unger RH. Lipotoxic heart disease in obese rats: implications for human obesity. Proc Natl AcadSci U S A (2000); 97: 1784-1789.

21. Roever L, and Borges ASR. Cardiac Steatosis: Is it Related to Ectopic Obesity, Insulin Sensitivity, Diabetes Mellitus and Metabolic Syndrome? J Cardiovasc Dis Diagn (2015); 3:e110.

22. DeFronzo RA. Insulin resistance, lipotoxicity, type 2 diabetes and atherosclerosis: the missing links. The Claude Bernard Lecture 2009. Diabetologia (2010); 53: 1270-1287.

23. Gurtl B, Kratky D, Guelly C, Zhang L, Gorkiewicz G, Das SK, Tamilarasan KP and Hoefler G. Apoptosis and fibrosis are early features of heart failure in an animal model of metabolic cardiomyopathy. Int $\mathrm{J}$ Exp Pathol (2009); 90: 338-346.

24. Wende AR, and Abel ED. Lipotoxicity in the heart. BiochimBiophysActa (2010); 1801: 311-319.

25. Schipke J, Banmann E, Nikam S,Voswinckel R, Kohlstedt K,Loot AE, Fleming I and Mühlfeld C. The number of cardiac myocytes in the hypertrophic and hypotrophic ventricle of the obese and calorie-restricted mouse heart. J Anat(2014) Nov; 225(5): 539-547.

26. Hayden MR, Chowdhury N, Govindrajan G, Karuparthi PR, Habibi J, Sowers JR. Myocardial myocyte remodeling and fibrosis in the cardiometabolic syndrome. J CardiometabSyndr (2006); 1: 326-33.

27. Noorman $M$, van der Heyden MA, van Veen TA, Cox MG, Hauer RN, de Bakker JM and van Rijen HV. Cardiac cell-cell junctions in health and disease: electrical versus mechanical coupling. J Mol Cell Cardiol (2009); 47: 23 -31.

28. Lakatta EG. Arterial and Cardiac Aging: Major Shareholders in Cardiovascular Disease Enterprises: Part III: Cellular and Molecular Clues to Heart and Arterial Aging. Circulation (2003); 107:490-497.

29. Kajstura J, Cheng W, Sarangarajan R, Li P, Li B, Nitahara JA, Chapnick S, Reiss K, Olivetti G, and Anversa P. Necrotic and apoptotic myocyte cell 
death in the aging heart of Fischer 344 rats. Am J Physiol (1996); 271: H1215-28.

30. Anna B and Nikolas G. Aging and cardiac fibrosis. Aging Dis (2011); 2(2): 158-173.

31. Lin J, Lopez EF, YufangJin Y, Remmen HV, Bauch T, Han HC and Lindsey ML. Age-Related Cardiac Muscle Sarcopenia: Combining experimental and mathematical modeling to identify mechanisms. ExpGerontol (2008); 43(4): 296-306.

32. Dai DF, Santana LF, Vermulst M, Tomazela DM, Emond MJ, MacCoss MJ, Gollahon K, Martin GM, Loeb LA, Ladiges WC, and Rabinovitch PS. Overexpression of catalase targeted to mitochondria attenuates murine cardiac aging. Circulation (2009); 119: 2789-97.

33. Kitzman DW, Gardin JM, Gottdiener JS, Arnold A, Boineau R, Aurigemma G, Marino EK, Lyles M, Cushman M, and Enright PL. Importance of heart failure with preserved systolic function in patients $>$ or $=65$ years of age. CHS Research Group. Cardiovascular Health Study. Am J Cardiol (2001); 87: 413-9.

34. Banday AA, MarwahaA ,Tallam LS, and Lokhandwala MF. Tempol reduces oxidative stress, improves insulin sensitivity, decreases renal dopamine D1 receptor hyperphosphorylation, and restores D1 receptor-G-protein coupling and function in obese Zuckerrats. Diabetes (2005); 54(7): 2219-2226.

35. Gupte AA, Liu JZ, and Renetal Y. Rosiglitazone attenuates age and diet-associated nonalcoholic steatohepatitis in male low density lipoprotein receptor knockout mice. Hepatology (2010); 52(6): 2001-2011.

36. Lee SR, Khamoui AV, Jo E, Park BS, Zourdos MC, Panton LB, Ormsbee MJ and Kim JS. Effects of chronic high fat feeding on skeletal muscle mass and function in middle-aged mice. Aging ClinExp Res (2015); 27: 403-411.

37. Nunes-Souza V, César-Gomes CJ, Da Fonseca LJ, GuedesGda S, Smaniotto S, and Rabelo LA. Aging Increases Susceptibility to High Fat Diet-
Induced Metabolic Syndrome in C57BL/6 Mice: Improvement in Glycemic and Lipid Profile after Antioxidant Therapy. Oxid Med Cell Longev (2016); 2016: 1987960.

38. Rondanelli M, Giacosa A, Morazzoni P, Guido D, Grassi M, Morandi G, Bologna C, Riva A, Allegrini $\mathrm{P}$ and Perna $\mathrm{S}$. Mediterrasian diet products that could raise HDL-Cholesterol: A systematic review. Biomed Res Int (2016); 2016: 2025687.

39. Rangboo V, Noroozi M, Zavoshy R, Rezadoost SA and Mohammadpoorasl A. The Effect of Artichoke Leaf Extract on Alanine Aminotransferase and Aspartate Aminotransferase in the Patients with Nonalcoholic Steatohepatitis. IntJ Hepato (2016); 2016: 4030476.

40. El-Sherif NM and Issa NM. The Possible Anti-fibrotic Effect of Artichoke on the Liver and Heart of Bile Duct Ligation Rat Model. AnatPhysiolBiochemInt J (2017); 2(1): 555577.

41. Zapolska-Downar D, Zapolski-Downar A, Naruszewicz M, Siennicka A, Krasnodbska B, and Kolodziej B. Protective properties of artichoke (Cynarascolymus) against oxidative stress induced in cultured endothelial cells and monocytes. Life Sci (2002); 71(24): 2897-2908.

42. Azzini E, Bugianesi R, F. Romano F, Di Venere D, Miccadei S, Durazzo A, Foddai MS, Catasta $\mathrm{G}$, Linsalata $\mathrm{V}$ and Mainai G. Absorption and metabolism of bioactive molecules after oral consumption of cooked edible heads of Cynarascolymus L. (Cultivar Violetto di Provenza) in human subjects: a pilot study. The Brit J Nutr(2007); 97(5):963-969.

43. Pittler MH, Thompson CJ, and Ernst E. Artichoke leaf extract for treating hypercholesterolaemia The Cochrane Database Syst Rev (2009): 4: CD003335.

44. Qiang, Z, Lee SO, Ye Z, Wu X and Hendrich S Qiang, Z., Lee, S.O., Ye, Z., Wu, X. and Hendrich, $\mathrm{S}$. Artichoke extract lowered plasma cholesterol and increased fecal bile acids in Golden Syrian hamsters. Phytother Res (2012); 26:1048-52. 
الملخص العربى

التأثثر التفاضلي للحمية عالية الدهون على عضلة القلب لإناث الفئران البالغة والمسنة والدور الوقائي المحتمل للعلاج بالخرشوف : دراسة نسيجية قياسية وتركيبية دقيقة

أسماء فتحي عبد المولى داوود1وهمت هريدي غفير هريدي2 1قسم الهستولوجي، كلية الطب، جامعة أسيوط، مصر ، قسم العلوم الطبية الأساسية ، كلية الطب هلبة ،

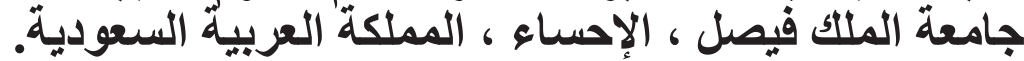
2قسم العلوم الطبية، كلية الطب، جامعة المجمعة، المملكة العربية السعودية

المقدمة: إن تو اجد فرط الدهون بالدم و الثنيخوخة معا من أثند الحالات خطورة والتي تؤدى إلى تدهور هائل في وظيفة القلب.

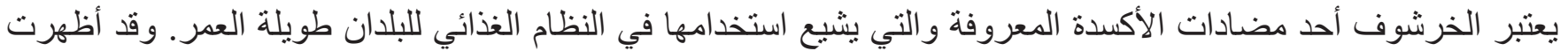

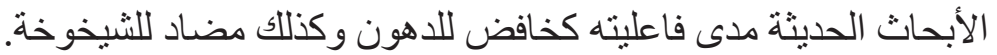
الهدف: يهذف هذا العمل إلى استكثاف الآثار المرضية للحمية عالية الدهون على عضلة القلب لدى الفئران البالغة، وكذللك تحديد ومقارنة ذلك بمدى تلف عضلة القلب لاى الفئر ان المسنة وتقييم الآثار المفيدة للخرشوف في تخفيف هذه الآثار الضارة.

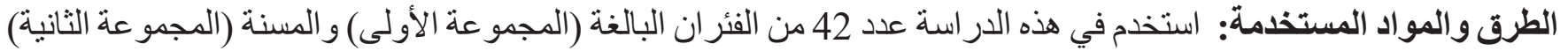

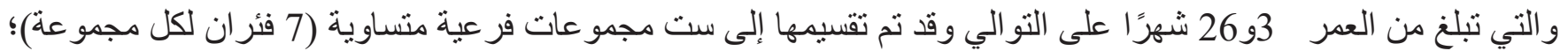

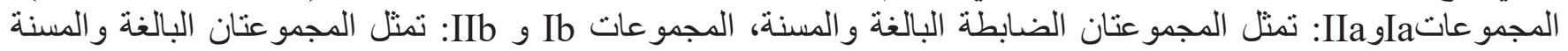

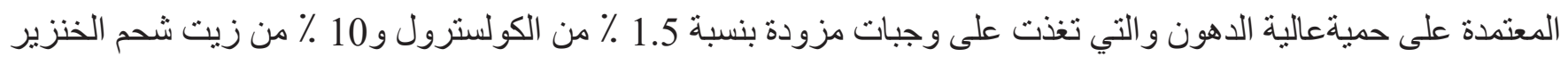

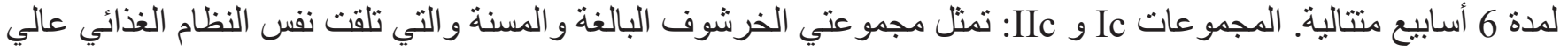

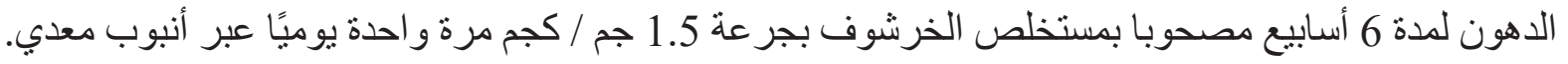

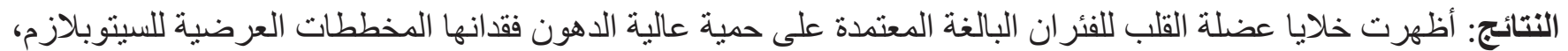

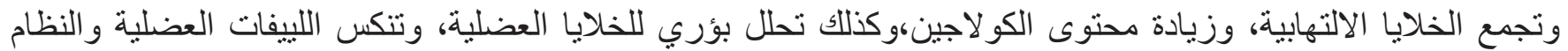

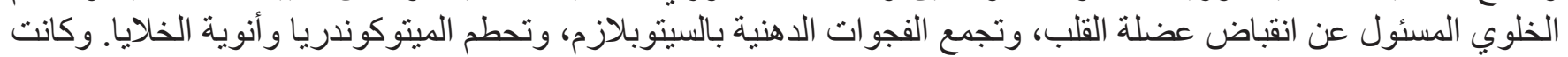

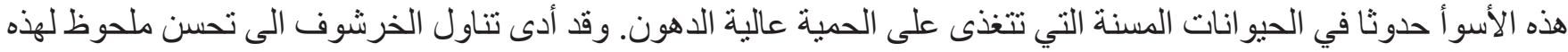
التغيير ات في كل من الفئران البالغة والنئة المسنة.

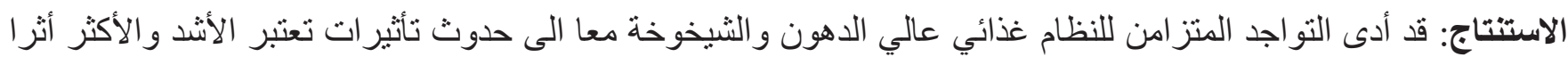
على خلايا عضلة|لقلب.وقد وجد أن الخرشوف ذو كفاءة عالية في تحسين هذه التأثنير ات الت. 